\title{
Experimental Study of Vortex Diffusers
}

Said Shakerin

University of the Pacific

Paul L. Miller

National Renewable Energy Laboratory

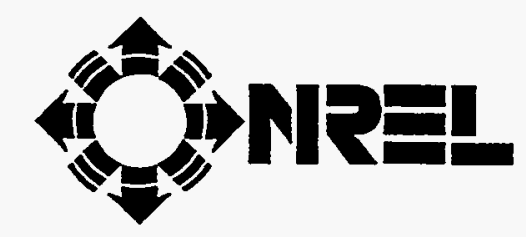

National Renewable Energy Laboratory 1617 Cole Boulevard Golden, Colorado 80401-3393

A national laboratory of the U.S. Department of Energy Managed by the Midwest Research Institute for the U.S. Department of Energy Under Contract No. DE-AC36-83CH10093 


\section{Experimental Study of Vortex Diffusers}

Said Shakerin

University of the Pacific

Paul Miller

National Renewable Energy Laboratory

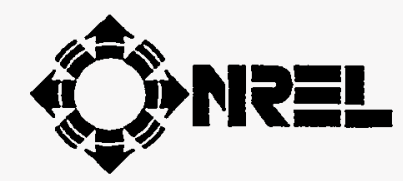

National Renewable Energy Laboratory 1617 Cole Boulevard

Golden, Colorado 80401-3393

A national laboratory of the U.S. Department of Energy Managed by the Midwest Research Institute for the U.S. Department of Energy under Contract No. DE-AC36-83CH19C9 $\mathrm{CTE}$

November 1995 


\section{NOTICE}

This report was prepared as an account of work sponsored by an agency of the United States government. Neither the United States government nor any agency thereof, nor any of their employees, makes any warranty, express or implied, or assumes any legal liability or responsibility for the accuracy, completeness, or usefulness of any information, apparatus, product, or process disclosed, or represents that its use would not infringe privately owned rights. Reference herein to any specific commercial product, process, or service by trade name, trademark, manufacturer, or otherwise does not necessarily constitute or imply its endorsement, recommendation, or favoring by the United States govemment or any agency thereof. The views and opinions of authors expressed herein do not necessarily state or reflect those of the United States govermment or any agency thereof.

Available to DOE and DOE contractors from:

Office of Scientific and Technical Information (OSTI)

P.O. Box 62

Oak Ridge, TN 37831

Prices available by calling (615) $576-8401$

Available to the public from:

National Technical Information Service (NTIS)

U.S. Department of Commerce

5285 Port Royal Road

Springfield, VA 22161

(703) $487-4650$

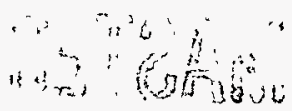

Printed on paper containing at least $50 \%$ wastepaper, including $10 \%$ postconsumer waste 


\section{Summary}

This report documents experimental research performed on vortex diffusers used in ventilation and airconditioning systems. The main objectives of the research were (1) to study the flow characteristics of isothermal jets issuing from vortex diffusers, (2) to compare the vortex diffuser's performance with that of a conventional diffuser, and (3) to prepare a report that disseminates the results to designers of ventilation and air-conditioning systems. This information is not available in the current technical literature.

To accomplish the research objectives, the researchers constructed a test platform and used diffusers donated by the manufacturers. Three diffusers were considered: a conventional round ceiling diffuser and two different styles of vortex diffusers. The researchers also used (experimental) equipment and instruments that they already had.

Measurements were taken of each diffuser to obtain a velocity map, velocity profile, and velocity decay. Flow visualization experiments were undertaken to capture the general behavior of jets issuing from the diffusers. A fog machine was used to enable whole-field visualization. This is a new and significant approach because the nontoxic fog, which meets stringent safety requirements, was produced easily in large quantities suitable for this application. A videotape of the flow visualizations was also produced.

Researchers found that, overall the vortex diffusers create slightly more induction (mixing) of ambient air in comparison to the conventional diffuser. This is caused by the turbulence resulting from the rotational motion of the air near the outlet of the vortex diffuser. The rotational motion disappears within three outlet diameters and the flow becomes radial. The vortex diffusers require larger duct static pressure at a given flow rate compared with the conventional diffuser. 


\section{Acknowledgments}

During the course of this research, the first author was partially supported by a Faculty Sabbatical Fellowship granted by Associated Western Universities, Inc., and the U.S. Department of Energy. He would like to extend special thanks to Dr. Ahmad Pesaran and Dr. Robert Farrington, the scientists who were his initial hosts, and Dr. Ren Anderson, Buildings Program manager. 


\section{Table of Contents}

\section{Page}

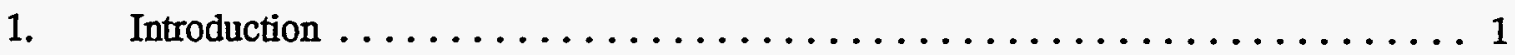

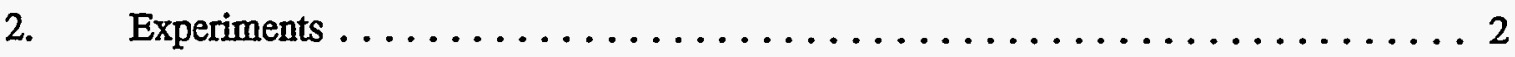

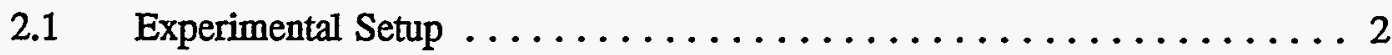

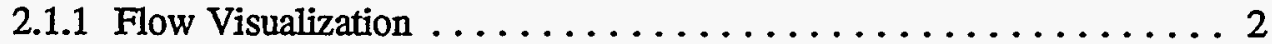

2.1.2 Diffuser Styles Tested $\ldots \ldots \ldots \ldots \ldots \ldots \ldots \ldots \ldots \ldots$

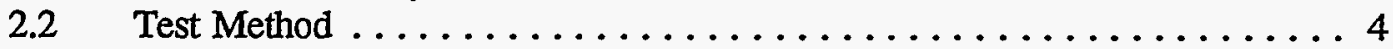

2.3 Measurement Uncertainty .................... 4

3. Results and Discussion $\ldots \ldots \ldots \ldots \ldots \ldots \ldots \ldots \ldots \ldots \ldots \ldots \ldots$

$3.1 \quad$ Validation of Test Apparatus $\ldots \ldots \ldots \ldots \ldots \ldots \ldots \ldots \ldots \ldots$

3.2 Vortex Diffusers . . . . . . . . . . . . . . . . . 7

3.3 Observations and Flow Visualizations ............... 14

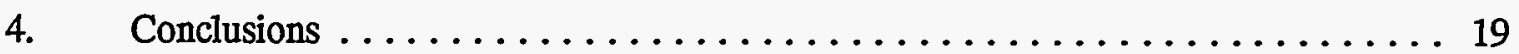

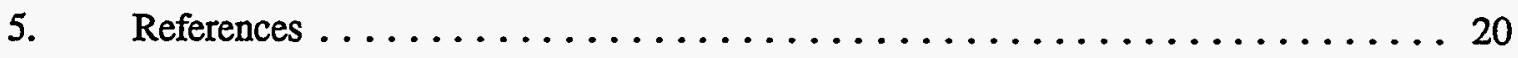

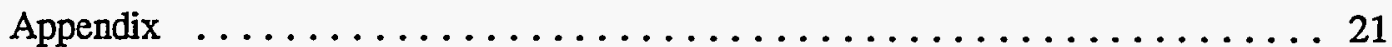

A.1 Description of the Fog Machine

A.2 MSDS for the Fog Liquid 


\section{List of Figures}

$\underline{\text { Page }}$

1. Test Apparatus $\ldots \ldots \ldots \ldots \ldots \ldots \ldots \ldots \ldots \ldots \ldots \ldots \ldots \ldots \ldots \ldots \ldots$

2. Diffusers Tested: (A) Conventional Diffuser, (B) Vortex Diffuser \#1

(C) Vortex Diffuser \#2 with Blank-Off Plate Open, (D) Vortex Diffuser \#2

with Blank-Off Plate Closed $\ldots \ldots \ldots \ldots \ldots \ldots \ldots \ldots \ldots \ldots \ldots \ldots \ldots$

3. Typical Flow Rate Measurement $\ldots \ldots \ldots \ldots \ldots \ldots \ldots \ldots \ldots \ldots \ldots \ldots \ldots \ldots$

4. Typical Velocity Measurement $\ldots \ldots \ldots \ldots \ldots \ldots \ldots \ldots \ldots \ldots \ldots$

5. Velocity Decay for Conventional Diffuser Tested in Up-Side-Down

Orientation Compared with Manufacturer's Catalog Data $\ldots \ldots \ldots \ldots \ldots$

6. Velocity Map for Conventional Diffuser $(\mathrm{Q}=71 \mathrm{~L} / \mathrm{s}) \ldots \ldots \ldots \ldots$

7. Velocity Profile for Conventional Diffuser $(Q=71 \mathrm{~L} / \mathrm{s}, \mathrm{R}=76 \mathrm{~cm}) \ldots \ldots$

8. Velocity Map for Vortex Diffuser $\# 1,(\mathrm{Q}=57 \mathrm{~L} / \mathrm{s}) \ldots \ldots \ldots \ldots$

9. Velocity Map for Vortex Diffuser $\# 2(\mathrm{Q}=93 \mathrm{~L} / \mathrm{s}) \ldots \ldots \ldots \ldots \ldots \ldots$

10. Velocity Profile for Vortex Diffuser $\# 1(\mathrm{R}=76 \mathrm{~cm}) \ldots \ldots \ldots \ldots \ldots$

11. Velocity Profile for Vortex Diffuser $\# 2(\mathrm{R}=76 \mathrm{~cm}) \ldots \ldots \ldots \ldots \ldots \ldots$

12. Velocity Decay for Vortex Diffuser $\# 1 \ldots \ldots \ldots \ldots \ldots \ldots \ldots \ldots \ldots \ldots$

13. Velocity Decay for Vortex Diffuser $\# 2 \ldots \ldots \ldots \ldots \ldots \ldots \ldots \ldots \ldots \ldots \ldots$

14. Composite Velocity Decay for Three Diffusers; (A) Data, (B) Best-Fit Lines . . . . . . 13

15. Duct Static Pressure for Three Diffusers $\ldots \ldots \ldots \ldots \ldots \ldots \ldots \ldots \ldots \ldots \ldots \ldots$

16. Ambient Air Motion Near Jet for Conventional Diffuser $(Q=71 \mathrm{~L} / \mathrm{s}):(A) R=0$,

$\mathrm{H}=46 \mathrm{~cm}$; (B) $\mathrm{R}=0, \mathrm{H}=30 \mathrm{~cm}$; (C) $\mathrm{R}=61 \mathrm{~cm}, \mathrm{H}=30 \mathrm{~cm} \ldots \ldots \ldots \ldots$

17. Ambient Air Motion Near Jet for Vortex Diffuser \#2 $(Q=71 \mathrm{~L} / \mathrm{s})$ : (A) $R=0$,

$\mathrm{H}=46 \mathrm{~cm}$; (B) $\mathrm{R}=0, \mathrm{H}=30 \mathrm{~cm} ;(\mathrm{C}) \mathrm{R}=61 \mathrm{~cm}, \mathrm{H}=30 \mathrm{~cm} \ldots \ldots \ldots \ldots$

18. Whole-Field Flow Visualization for Conventional Diffuser $\ldots \ldots \ldots \ldots \ldots \ldots \ldots$

19. Whole-Field Flow Visualization for Vortex Diffuser $\# 2 \ldots \ldots \ldots \ldots \ldots$ 


\section{Nomenclature}

$\begin{array}{ll}\text { A } & \text { area } \\ \text { An } & \text { diffuser area factor, calculated }(\mathrm{Q} / \mathrm{Vk}) \\ \text { CD } & \text { diffuser neck area, calculated }\left(\pi \mathrm{D}^{2} / 4\right) \\ \text { D } & \text { conventional diffuser (round ceiling diffuser) } \\ \text { H } & \text { diffuser neck diameter } \\ \text { K } & \text { vertical distance from diffuser } \\ \text { Q } & \text { proportionality constant for jet zone III } \\ \text { R } & \text { flow rate } \\ \text { V } & \text { radial distance from diffuser center } \\ \text { Vk } & \text { velocity } \\ \text { Vn } & \begin{array}{l}\text { Average outlet velocity, velocity measured with standard instrument in specified } \\ \text { location }\end{array} \\ \text { VD1 } & \text { neck velocity, calculated (Q/An) } \\ \text { vortex diffuser \#1 } & \text { vortex diffuser \#2 }\end{array}$





\section{Introduction}

Air diffusers are important components of ventilation and air-conditioning systems. The comfort level of occupants and the efficient delivery of air in a building depend on, among other factors, properly designed and selected diffusers. Many kinds of diffusers are manufactured to meet specific requirements and, quite often, each kind is available in different styles. For example, one common kind is the round ceiling diffuser, which is available in both adjustable and fixed geometries.

Another kind of diffuser is the vortex (swirl) diffuser. The jet issuing from this diffuser has both translational and rotational velocity. The rotation is imposed on the main flow as the air passes through a series of angled vanes located in the diffuser. Some manufacturers of vortex diffusers claim that, because of the rotational component, the diffusers have significantly higher induction (mixing) than do conventional diffusers. However, the effect of this rotational component has not been well documented.

Although vortex diffusers have been manufactured since the 1960 s, information available on vortex jet characteristics and performance is limited. The ASHRAE Handbook of Fundamentals did not even mention this type of diffuser until its most recent revision (ASHRAE 1993). A literature search did not identify a specific study of vortex diffusers used in air conditioning.

However, that vortex motion in the occupant zone has been investigated as a means of ventilation, [see Nagasawa and Matsui (1988), Nagasawa et al. (1990), Yamaguchi et al. (1991), and Nagasawa (1992)]. For example, in one experimental study (Nagasawa et al. 1990), air was distributed through holes in four columns situated near the perimeter of a table of five smokers to create a vortical circulation around the table. The retum duct was above the table. Results showed that the contaminants (i.e., cigarette smoke particles) were not transported to the rest of the room, but they were instead contained to a space around the vortex axis.

Because of the lack of technical information on vortex diffusers, and in accord with ongoing research at NREL's Ventilation and Indoor Air Quality Laboratory, we decided that an experimental investigation of vortex diffusers was appropriate. The objectives set for the research were (1) to study the flow characteristics of isothermal jets issuing from two different styles of vortex diffusers, (2) to compare the vortex diffuser's performance with that of a conventional diffuser, (3) to see if the standard test methods could be used to obtain the characteristics of vortex diffusers, and (4) to prepare a report that would disseminate the results to designers of ventilation and air-conditioning systems. 


\section{Experiments}

In this section, we first describe the experimental setup and method and follow that with a list of measurement uncertainties.

\subsection{Experimental Setup}

To accomplish the research objectives, the researchers designed and assembled a test apparatus as shown schematically in Figure 1. It consists of a $3.7 \mathrm{~m} \mathrm{x} 3.7 \mathrm{~m}$ (12 ft x $12 \mathrm{ft}$ ) plywood platform (or table) with a center opening to support a diffuser in an up-side-down (jet issuing upward) arrangement, flush with the surface. This arrangement was selected for convenience of assembly and measurements. The test apparatus was housed in a large warehouse.

The up-side-down arrangement in this study differs from the one prescribed in standard test methods (e.g., ANSI-ASHRAE 70-1991), in which a diffuser is installed in a ceiling-type arrangement. Note that the direction of air flow upstream of the diffuser in this study is against gravity which should not pose a problem as long as the flow is isothermal. This was verified by testing a conventional diffuser in the up-side-down arrangement and comparing results with published data from the manufacturer's catalog.The manufacturer used the standard method of test. The details of this validation are presented later with the results.

The air-flow loop was comprised of an air blower, a mass flow transducer with a readout device, $20 \mathrm{~cm}$ (8in) diameter sheet metal duct, and the diffuser. There is about $60 \mathrm{~cm}$ (25 in.) of straight vertical duct upstream of the diffuser. A window screen is used at the last elbow fitting to help straighten the flow.

Other instruments used in this study include an omnidirectional hot-wire anemometer (TSI-1640) for velocity measurements, a thermocouple (type $\mathrm{J}$ ) with a readout device, a velometer (Alnor Series 6000) for average outlet velocity measurements, and a pressure sensor (Alnor CompFlow 8530D-1) for duct static pressure measurements. To minimize the intrusiveness of the measuring probe, the telescopic hot-wire anemometer probe is attached vertically to the end of a 60-cm horizontal rod supported by a laboratory stand. One pressure tap is installed in the duct 1.5 diffuser neck diameters (1.5D) upstream of the diffuser.

\subsubsection{Flow Visualization}

In addition to the velocity point measurements, researchers conducted several tests to visualize the jets issuing from the diffusers and to observe the induction of ambient air into the jets.

A fog machine is used to visualize the jet flow, and smoke from three burning punks is used to observe the motion of the ambient air near the diffuser. The contrast between the fog produced by the machine and the smoke generated by the punks is especially useful for the flow visualization. The fog is introduced into the duct upstream of the diffuser at the point shown in Figure 1. The punks are positioned above the test platform at selected vertical and radial locations.

The fog machine is typically used for special effects in movie and stage productions. A nontoxic liquid is pumped into the machine and atomized to a very fine fog, which can easily be produced in a large, controllable quantity. This is a new and significant approach to flow visualization, considering the stringent safety requirements that must be observed. After each run, distilled water is circulated 


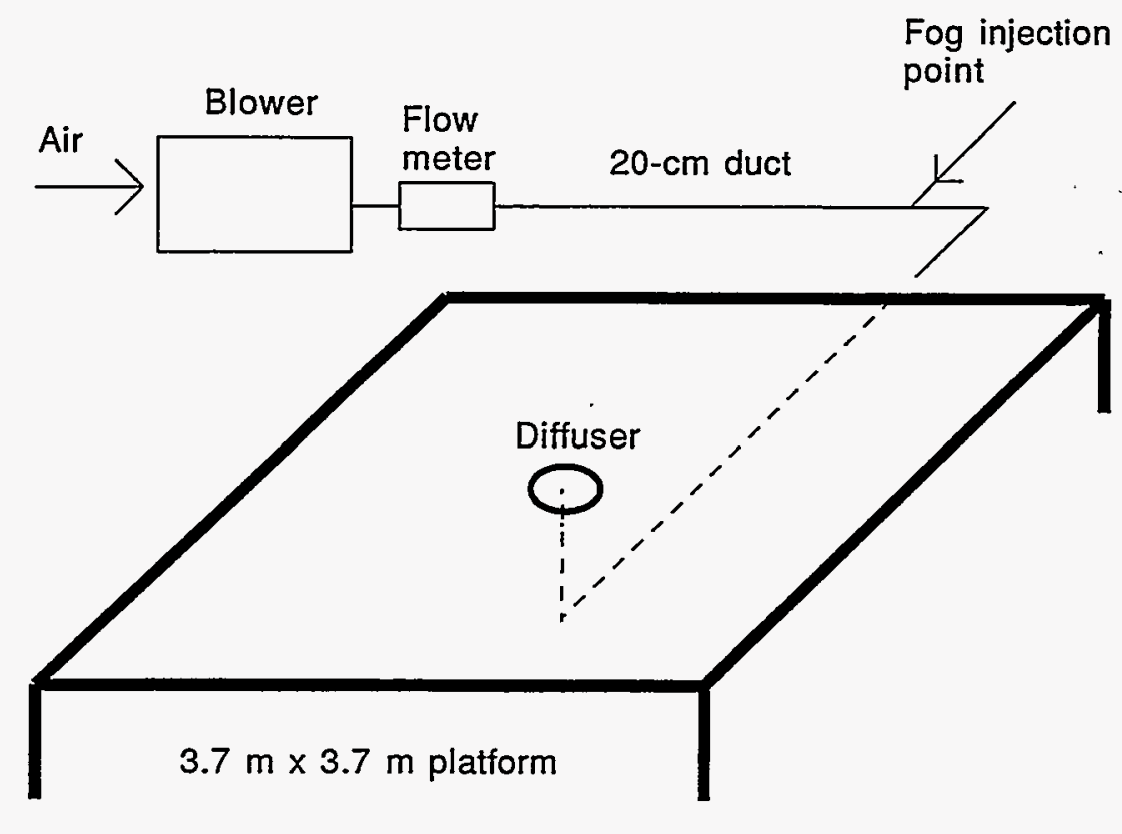

vc-hg64-a2702-15

Figure 1. Test apparatus

through the machine to clear the fog fluid. A more detailed description of the fog machine and the Material Safety Data Sheet (MSDS) for the fog liquid are included in the appendix.

A photographic camera, attached to the test platform on one side, and a video camera are used to record flow visualizations. The video camera is positioned either $1.5 \mathrm{~m}(5 \mathrm{ft})$ above the center of the test platform or on the side. It is operated with a remote control device. Special lighting is not necessary, but the platform is covered by black felt fabric to provide proper contrast in the background for most of the tests. Black and white film (Kodak TriX Pan, 400 ASA) is used for still photography.

In addition to the whole-field visualization, the researchers observed the flow direction at several locations around the diffuser, using a fine strip of mylar taped to the tip of a long slender rod supported by a laboratory stand.

\subsubsection{Diffuser Styles Tested}

A round ceiling diffuser (hereafter called the "conventional diffuser") and two different styles of vortex diffusers were tested in this study (see Figure 2). These diffusers are designed for ceiling installation. A short description of each follows.

The conventional diffuser has a neck diameter of $15 \mathrm{~cm}(6 \mathrm{in}$.) and two fixed cones [Figure 2(A)]. This diffuser was tested to validate the up-side-down test arrangement and also to compare it's performance with that of the vortex diffusers.

As shown in Figure 2(B), vortex diffuser \#1 has 12 identical, fixed radial vanes in a fan-type arrangement at the center of the diffuser face plate $[61 \mathrm{~cm} \times 61 \mathrm{~cm}(24 \mathrm{in} . \times 24 \mathrm{in}$.)]. The neck diameter is $18 \mathrm{~cm}$ (7.1 in.). Each vane has a slanted surface followed by a horizontal section. This 

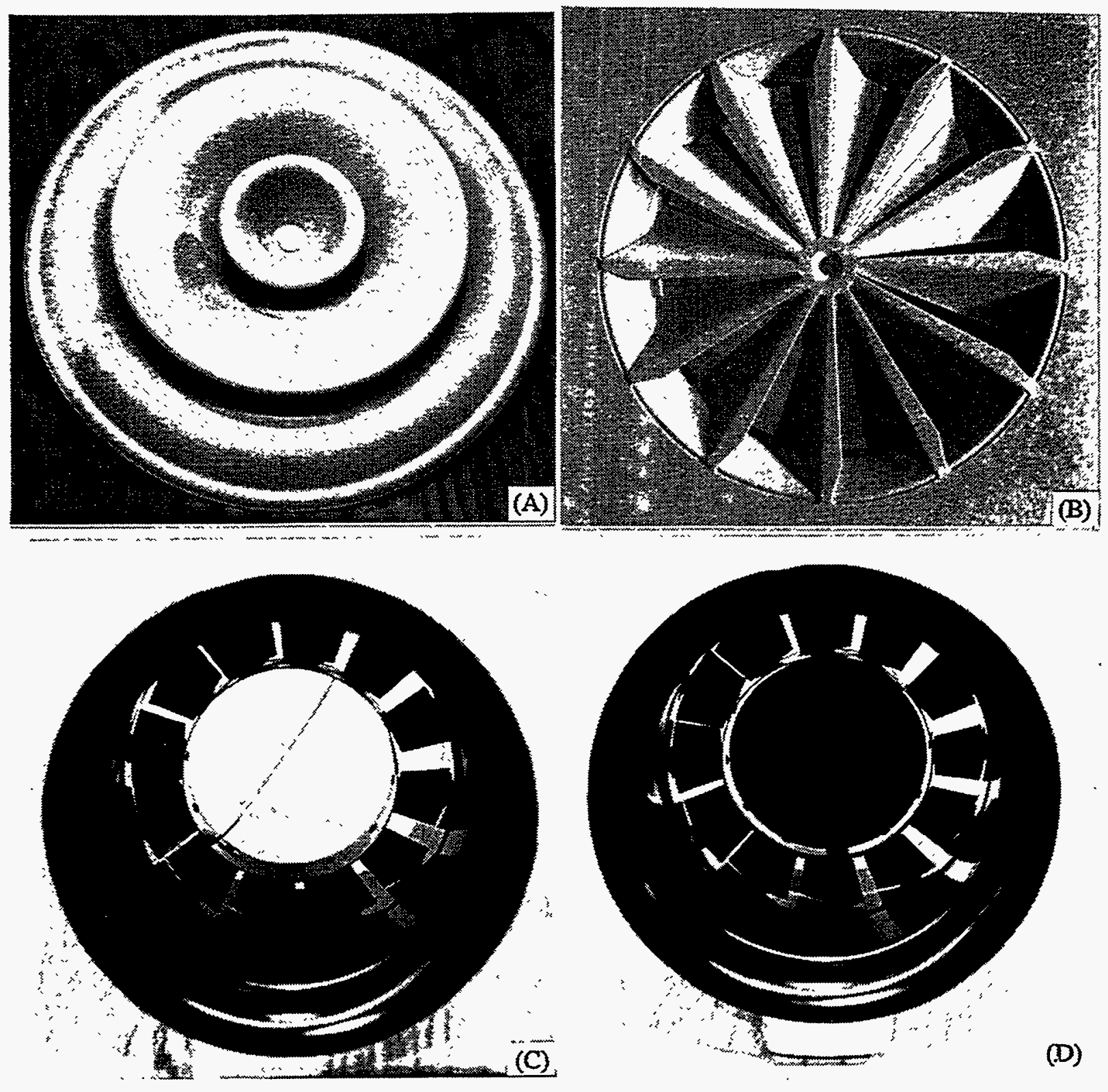

Figure 2. Diffusers tested: (A) conventional diffuser, (B) vortex diffuser \#1, (C) vortex diffuser \#2 with blank-off plate open, (D) vortex diffuser \#2 with blank-off plate closed 
particular shape forces air to rotate around a vertical axis as the air flows horizontally out of the diffuser.

Vortex diffuser \#2 [Figures 2(C) and 2(D)], has a neck diameter of $20 \mathrm{~cm}(8 \mathrm{in}$.) and a cylindrical shape with a smooth, rounded outlet. The diffuser is divided into a central and an annular passageway. There are 12 straight vanes with adjustable angles positioned in the annulus. These vanes create rotation in the flow. The central passageway is equipped with a blank-off plate, which can be used to control the outflow direction. The air flow is vertical (paraliel to the diffuser axis) when the blank-off plate is open, and it is horizontal when the blank-off plate is fully closed, which was the only configuration of current interest.

The last portion of the duct (i.e., between the last elbow and the diffuser) was sized to match the neck size of the diffuser being tested.

\subsection{Test Method}

Each diffuser was tested at several different flow rates. Some of the runs were repeated to investigate the repeatability in data. The flow rate was measured for three minutes and then averaged. A typical

flow rate measurement is shown in Figure 3. At a given flow rate, researchers took numerous velocity point measurements in the radial, angular, and axial directions obtained with the omnidirectional hotwire anemometer. They used a 3-minute observation interval to obtain the average velocity for each measurement point. Figure 4 shows a typical velocity measurement.

Temperature was measured at the diffuser outlet and the blower inlet. Barometric pressure was measured in a nearby laboratory. The barometric pressure and ambient air temperature are needed for correcting the velocity and flow rate readings from the standard condition (instrument setting) to the test condition in Denver, Colorado at an elevation of $1610 \mathrm{~m}$ (5283 ft) elevation.

\subsection{Measurement Uncertainty}

Researchers estimated the following uncertainties from repeated measurements, comparisons among results obtained from different instruments measuring the same quantity, and their own judgment:

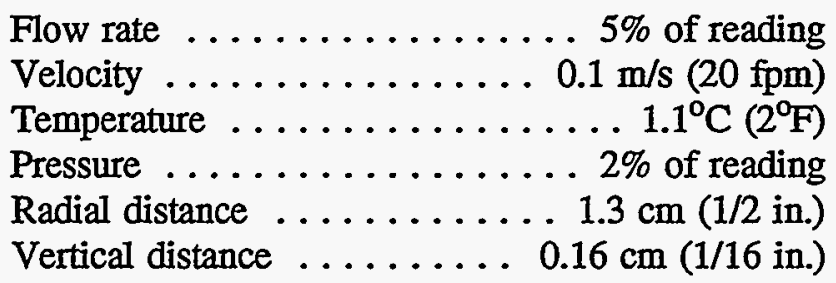




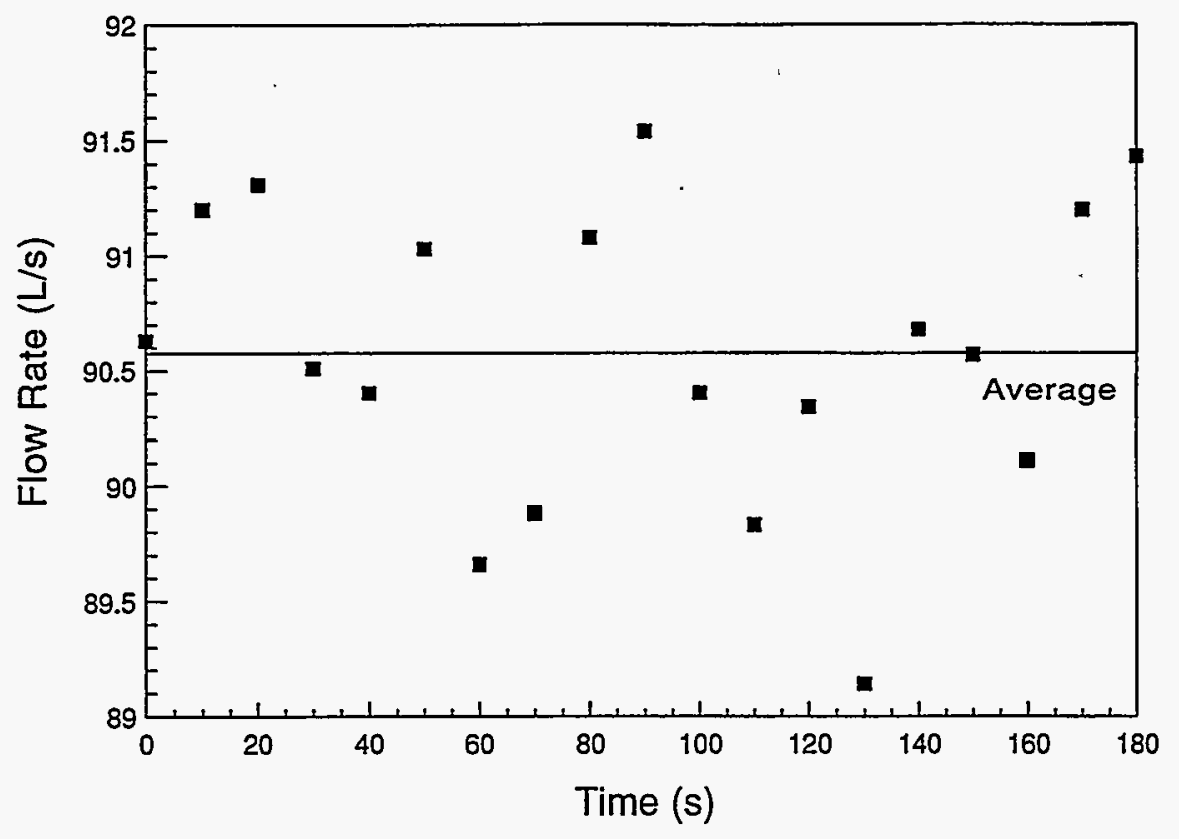

vc-hg64-a2702-01

Figure 3. Typical flow rate measurement

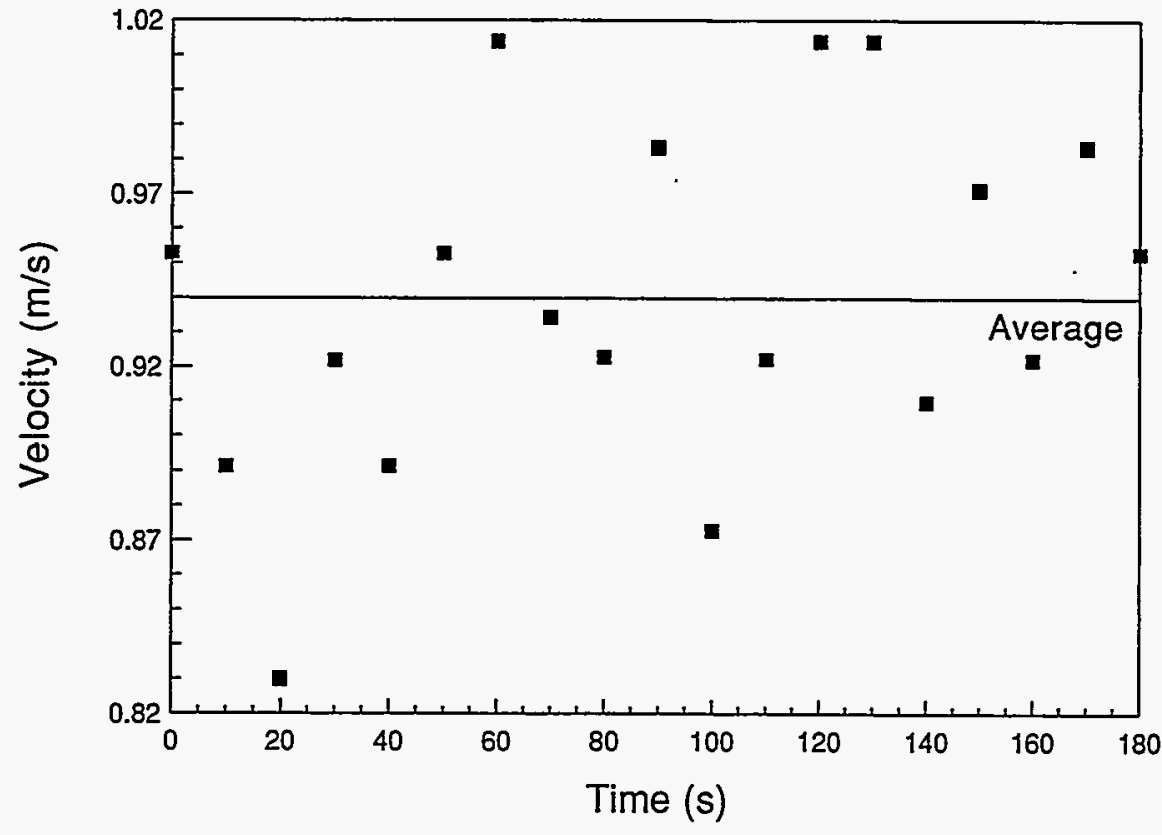

vc-hg64-a2702-02

Figure 4. Typical velocity measurement 


\section{Results and Discussion}

The results of this study include validation of the test apparatus, the performance data for vortex diffusers, and comparison with the conventional diffuser.

\subsection{Validation of Test Apparatus}

As stated earlier, the diffusers were tested in an up-side-down arrangement. Presumably, the up-sidedown test and the standard test (where a diffuser is installed in a ceiling) should produce the same results as long as airflow is isothermal. The researchers verified this using a conventional diffuser in the apparatus.

Velocity at the outlet was measured with an Alnor Velometer according to the procedure specified by the manufacturer. This measurement was used to determine the velocity factor, which was later used to produce velocity decay information.

Figure 5 shows, in the standard format, the velocity decay obtained from this study and that from the diffuser manufacturer for the same style of conventional diffuser. As expected, the data fall on the slope of zone III of jet expansion. Note that the data in the manufacturer's catalog are rounded to the nearest foot. The catalog data were extended to cover $0.5 \mathrm{ft}$ on each side of the data points, shown by a series of horizontal bars in Figure 3. The data obtained for validation compare favorably with the manufacturer's data, especially considering the experimental uncertainty, the manufacturing variations for the same diffuser, and the variability of testing at different laboratories (Miller and Ball 1983). Hence, the use of and up-side-down test arrangement produces valid results.

For completeness, the velocity map and velocity profile for the conventional diffuser are shown in Figures 6 and 7, respectively. Figure 6 shows that the diffuser provides a uniform radial velocity distribution. The low velocity points match the locations of the three radial ribs that support the cones in this diffuser. As expected, and as shown in Figure 7, the point of maximum velocity was within $2 \mathrm{~cm}$ ( 1 in.) of the platform's surface.

\subsection{Vortex Diffusers}

Each of the vortex diffusers were tested under three different flow rates. Figures 8-13 show the results in terms of the velocity map, velocity profile, and velocity decay for the vortex diffusers. Figures 8 and 9 show that the velocity distribution is radially uniform for both diffusers. However, careful and time-consuming individual vane adjustments were necessary in the case of vortex diffuser \#2 before the uniform velocity distribution was established. Vortex diffuser \#1 had fixed vanes.

The flow rate specifications for the diffusers are:

CD: $80-315 \mathrm{cfm}$ (size 6 in.)

VD1: $94-150 \mathrm{cfm}$ (size $180 \mathrm{~mm}$ )

VD2: $125-300 \mathrm{cfm}$ (size $8 \mathrm{in}$.) 


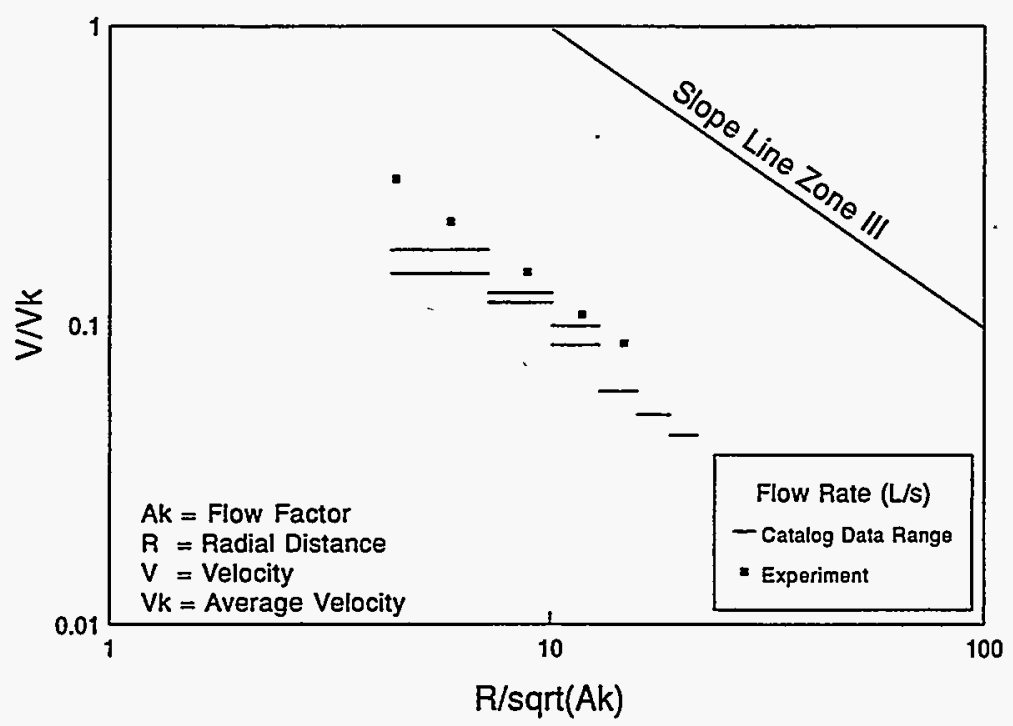

vc-hg64-a2702-03

Figure 5. Velocity decay for conventional diffuser tested in up-side-down orientation compared with manufacturer's catalog data

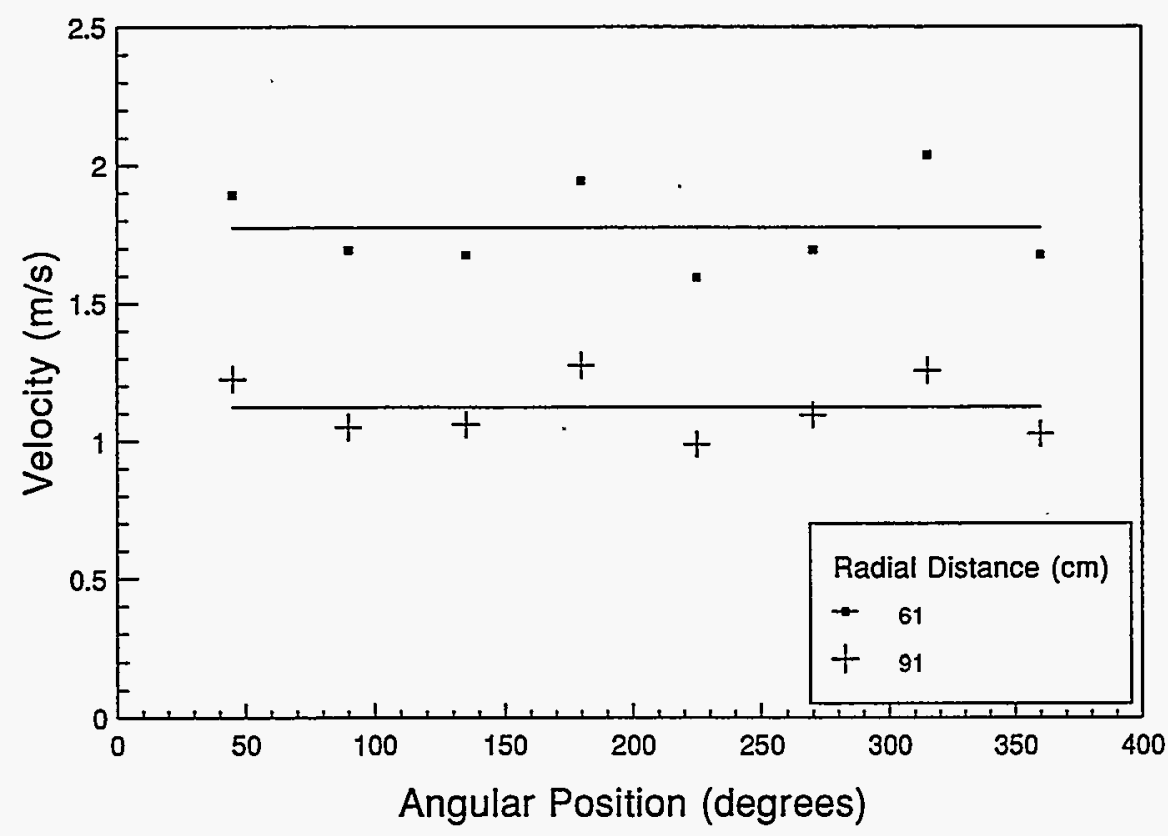

vc-hg64-a2702-04

Figure 6. Velocity map for conventional diffuser $(Q=71 \mathrm{~L} / \mathrm{s})$ 


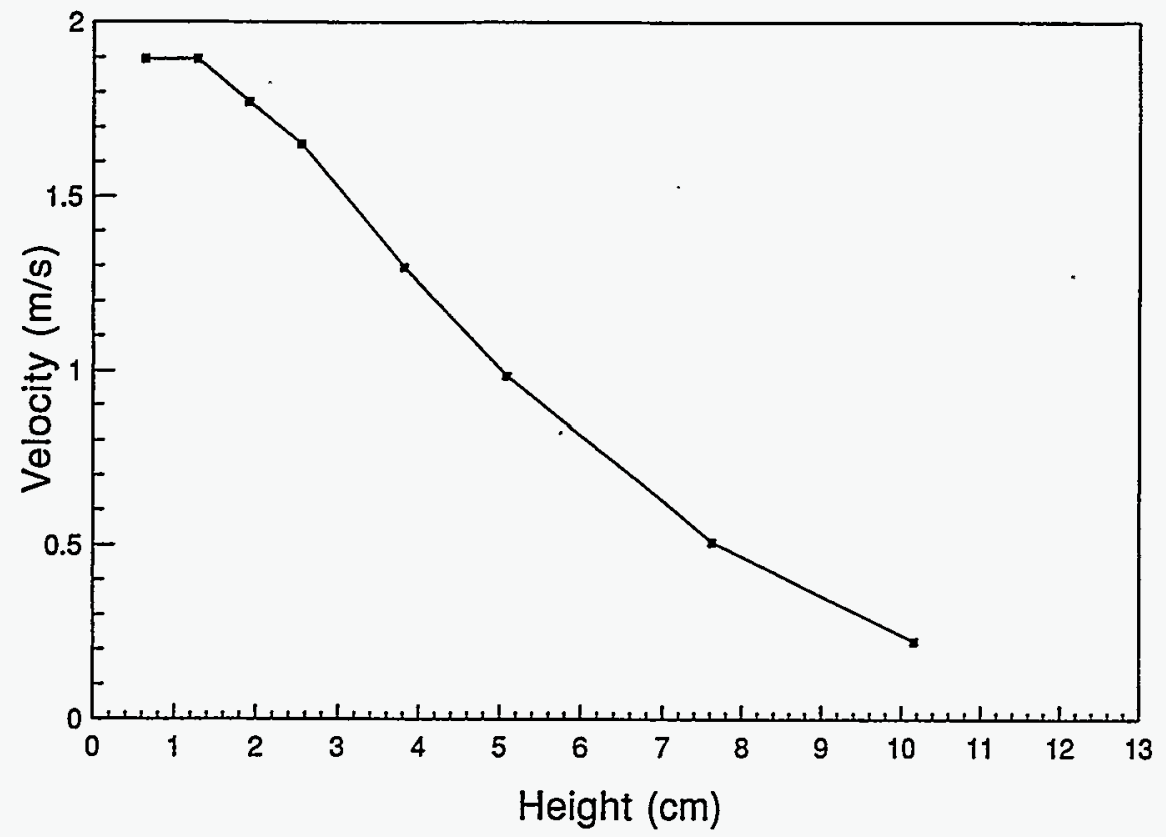

vc-hg64-a2702-05

Figure 7. Velocity profile for conventional diffuser $(Q=71 \mathrm{Ls}, R=76 \mathrm{~cm})$

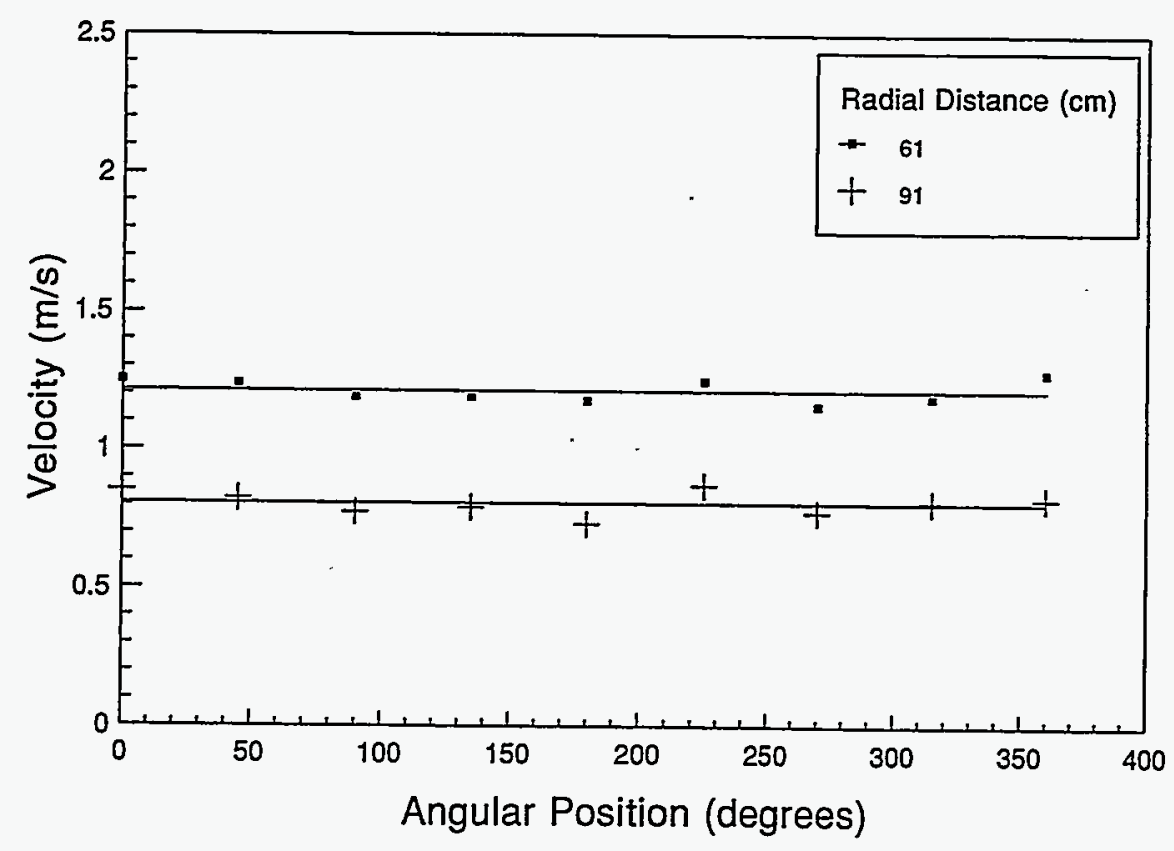

vc-hg64-a2702-06

Figure 8. Velocity map for vortex diffuser \#1, $(Q=57 \mathrm{~L} / \mathrm{s})$ 


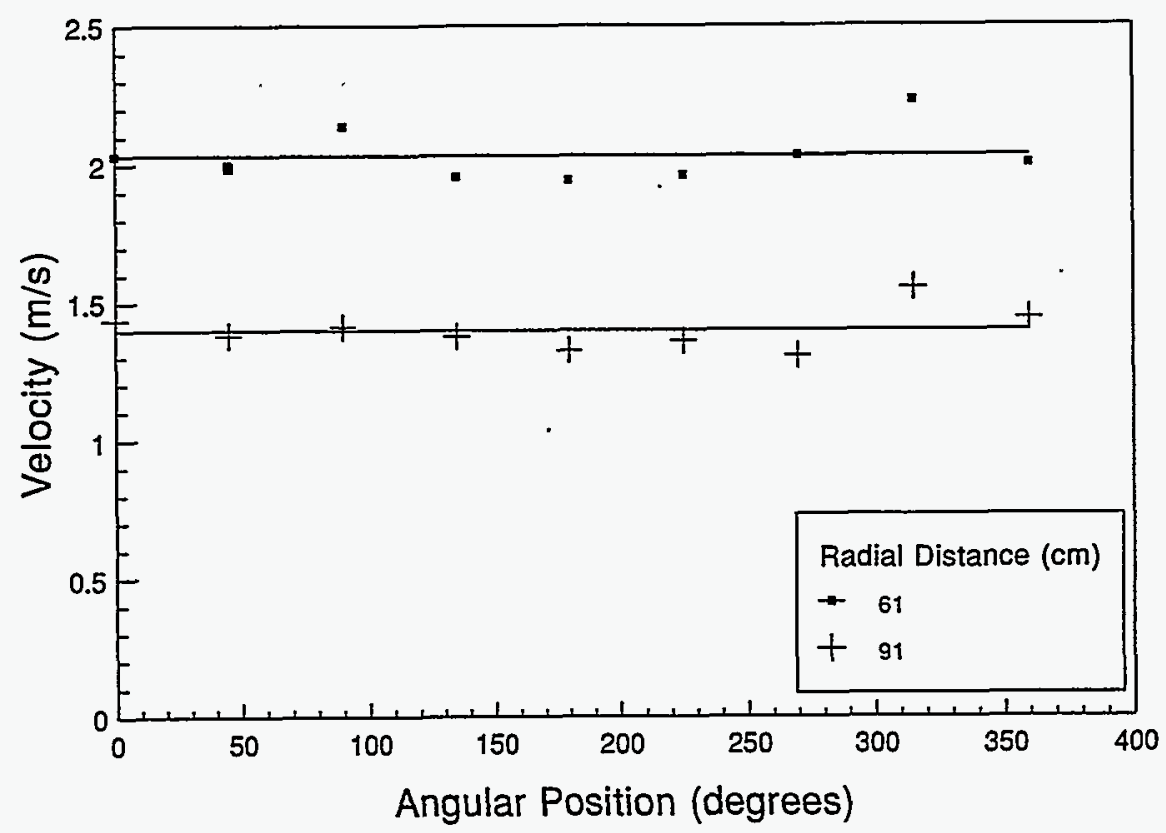

vc-hg64-a2702-07

Figure 9. Velocity map for vortex diffuser \#2 ( $Q=93 \mathrm{~L} / \mathrm{s})$

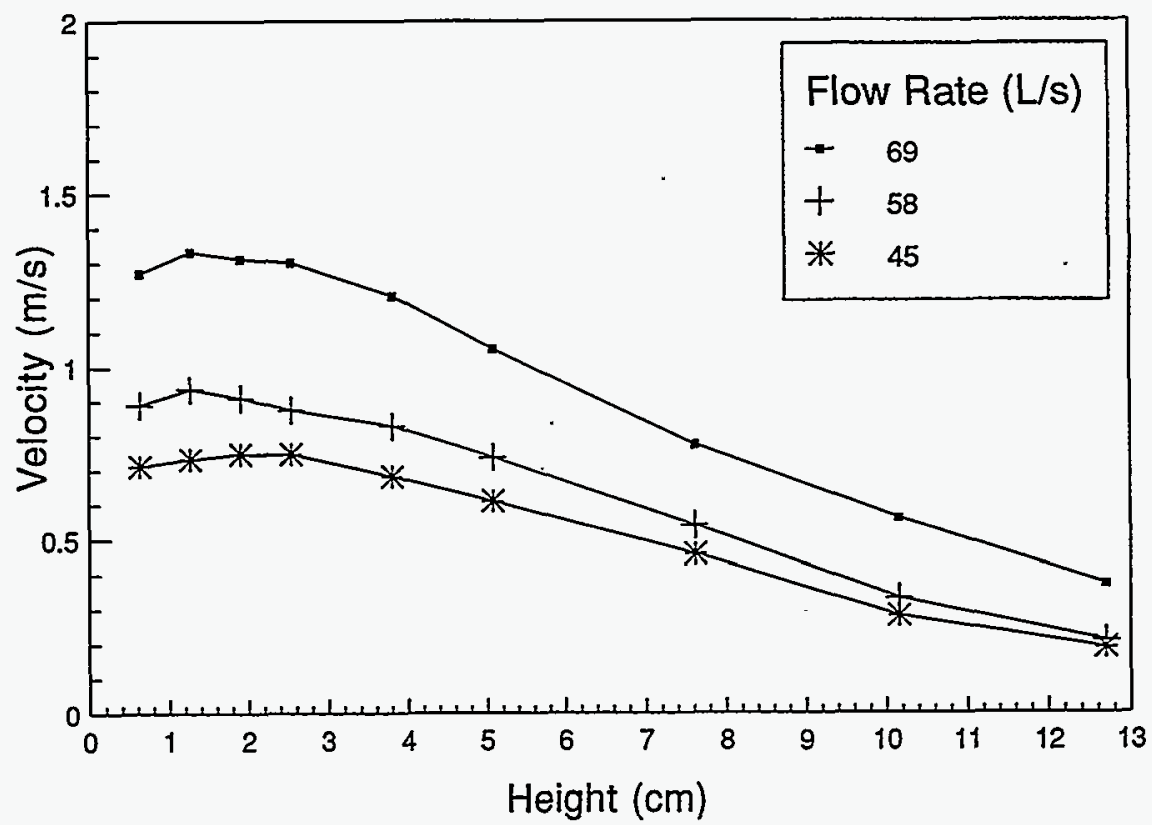

vc-hg64-a2702-08

Figure 10. Velocity profile for vortex diffuser \#1 $(R=76 \mathrm{~cm})$ 


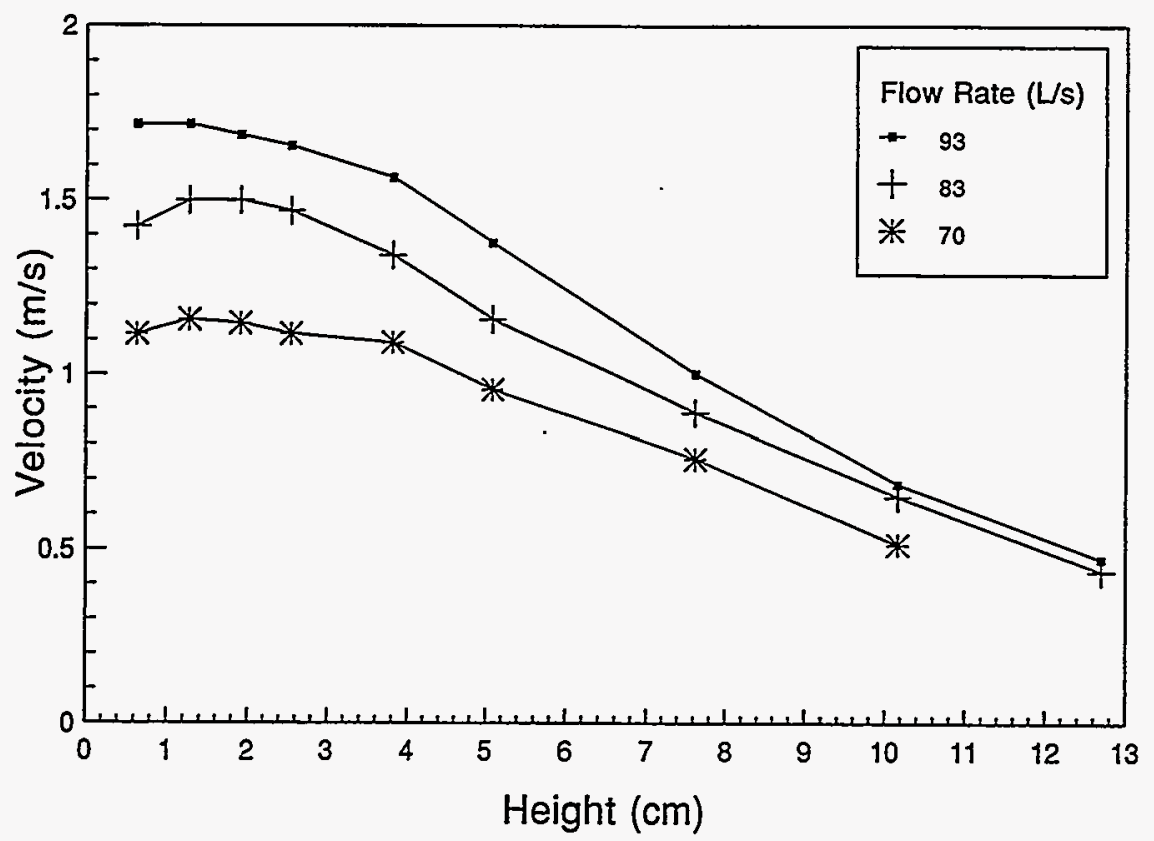

vc-hg64-2702-09

Figure 11. Velocity profile for vortex diffuser $\# 2(R=76 \mathrm{~cm})$

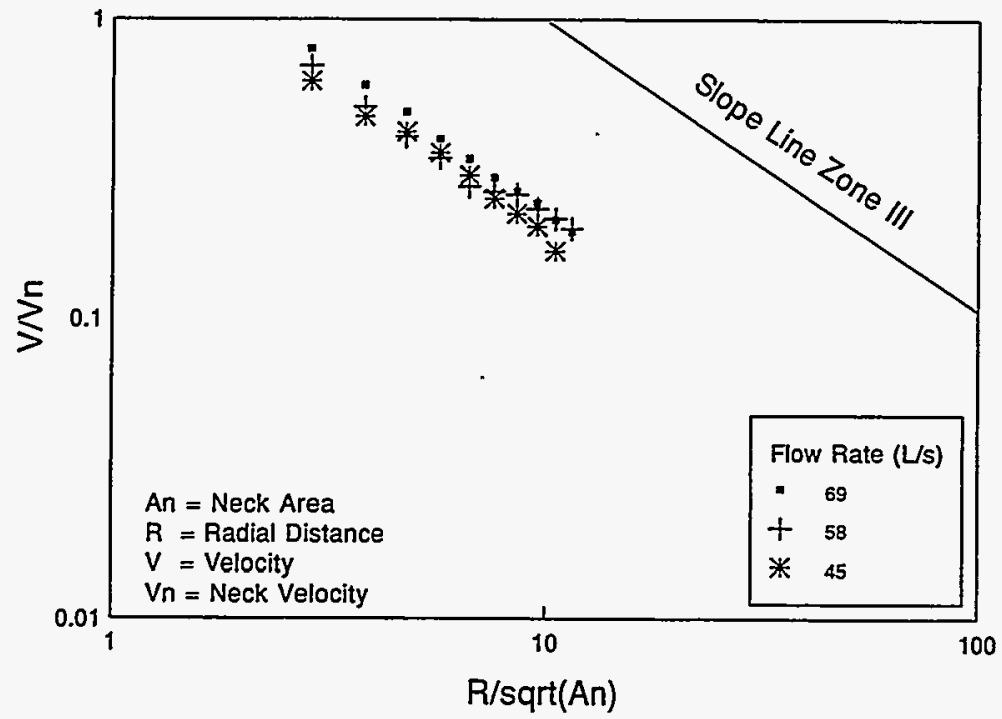

vc-hg64-a2702-10

Figure 12. Velocity decay for vortex diffuser \#1 


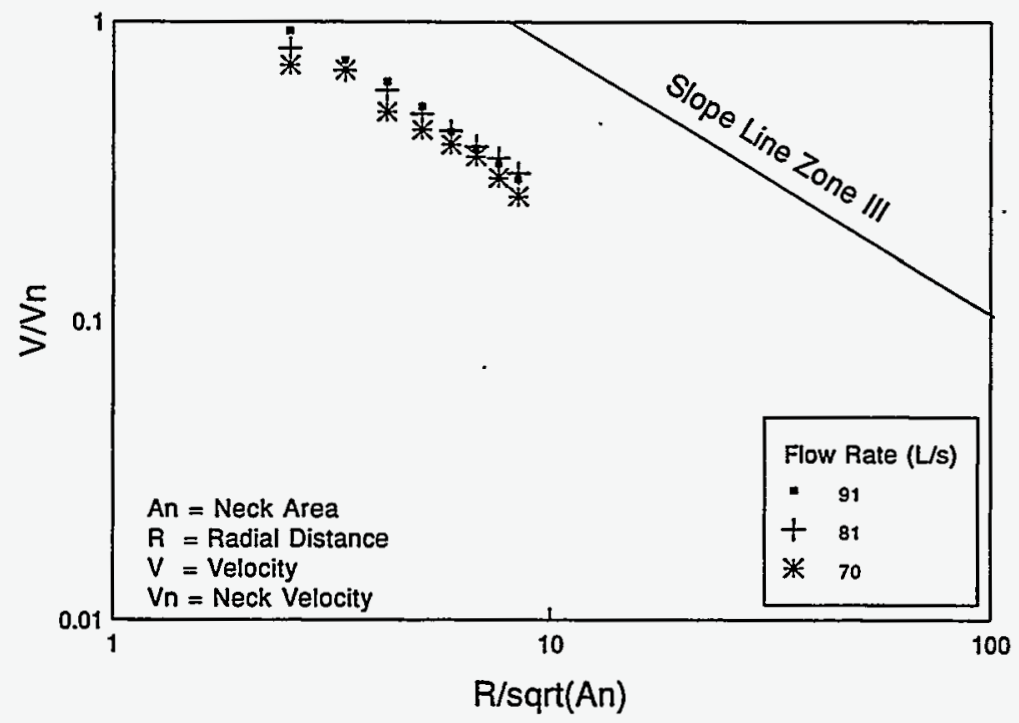

vc-hg64-a2702-11

Figure 13. Velocity decay for vortex diffuser \#2

Figures 10 and 11 show the velocity profiles for the two vortex diffusers at a radial distance of $76 \mathrm{~cm}$ (30 in). The maximum point of velocity is within $2 \mathrm{~cm}(0.8 \mathrm{in}$.) of the surface for all the cases shown which is similar to established performance of conventional diffusers (Koestel, 1957).

Figures 12 and 13 show velocity decay data and that the typical zone III of jet expansion is established for each of the vortex diffusers, analagous to the conventional diffuser. The format of Figures 12 and 13 differs from the standard format in that the neck velocity and neck area are used for normalization, whereas the average outlet velocity (measured with a specified instrument and method) and area factor are used for normalization in the standard format (ASHRAE 70-91). For vortex diffuser \#1, the standard normalization approach was not used because the average outlet velocity could not be measured; we were unable to arraive at a meaningful area factor-it was dependent on the flow rate. In the case of vortex diffuser \#2, it was impractical to use the standard specified instrument to measure the velocity because of the long throat of the diffuser.

Figure 14(A) presents a composite of velocity decay data for the three diffusers tested; the best (least squares) fits to the same data are shown in Figure 14(B). The main insight obtained from Figure $14(\mathrm{~B})$ is that the data for the vortex diffusers show a slightly higher value of $\mathrm{K}$. The numerical value of $\mathrm{K}$ is found at the intersection of the best-fit curve and the horizontal line at which $\mathrm{V} / \mathrm{Vn}=1$. The significance of $\mathrm{K}$ is apparent in the following well-known equation (ASHRAE, 1993):

$$
\frac{\mathrm{V}}{\mathrm{Vn}}=\mathrm{K} \frac{\sqrt{\mathrm{An}}}{\mathrm{R}}
$$


Figure 14-A

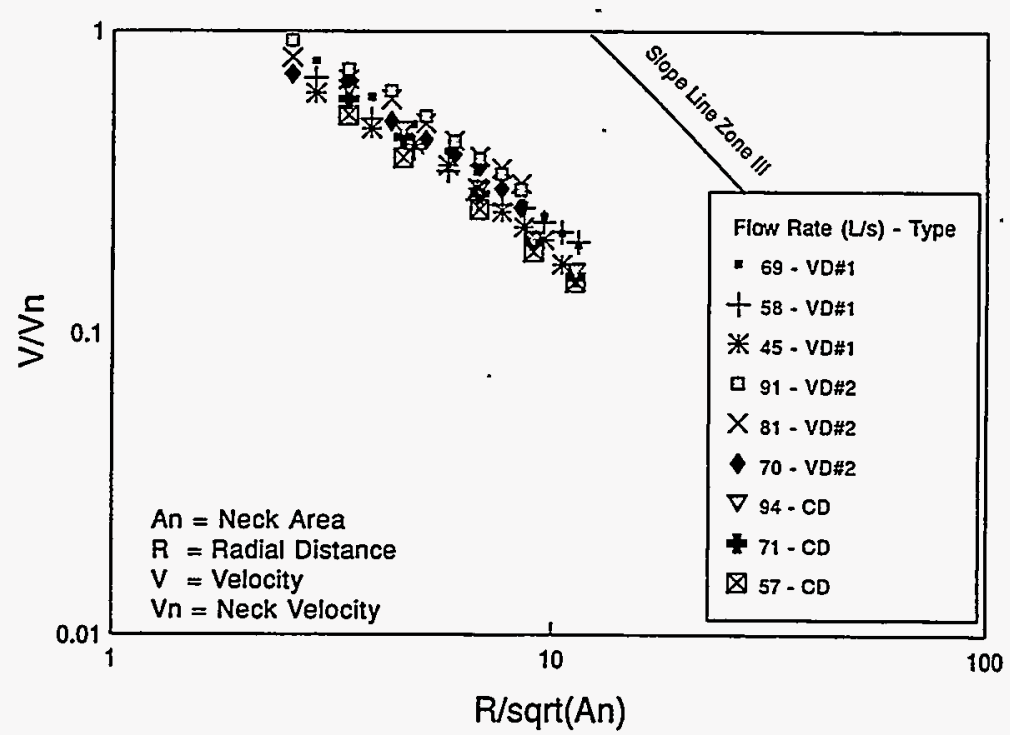

vc-hg64-a2702-12

Figure 14-B

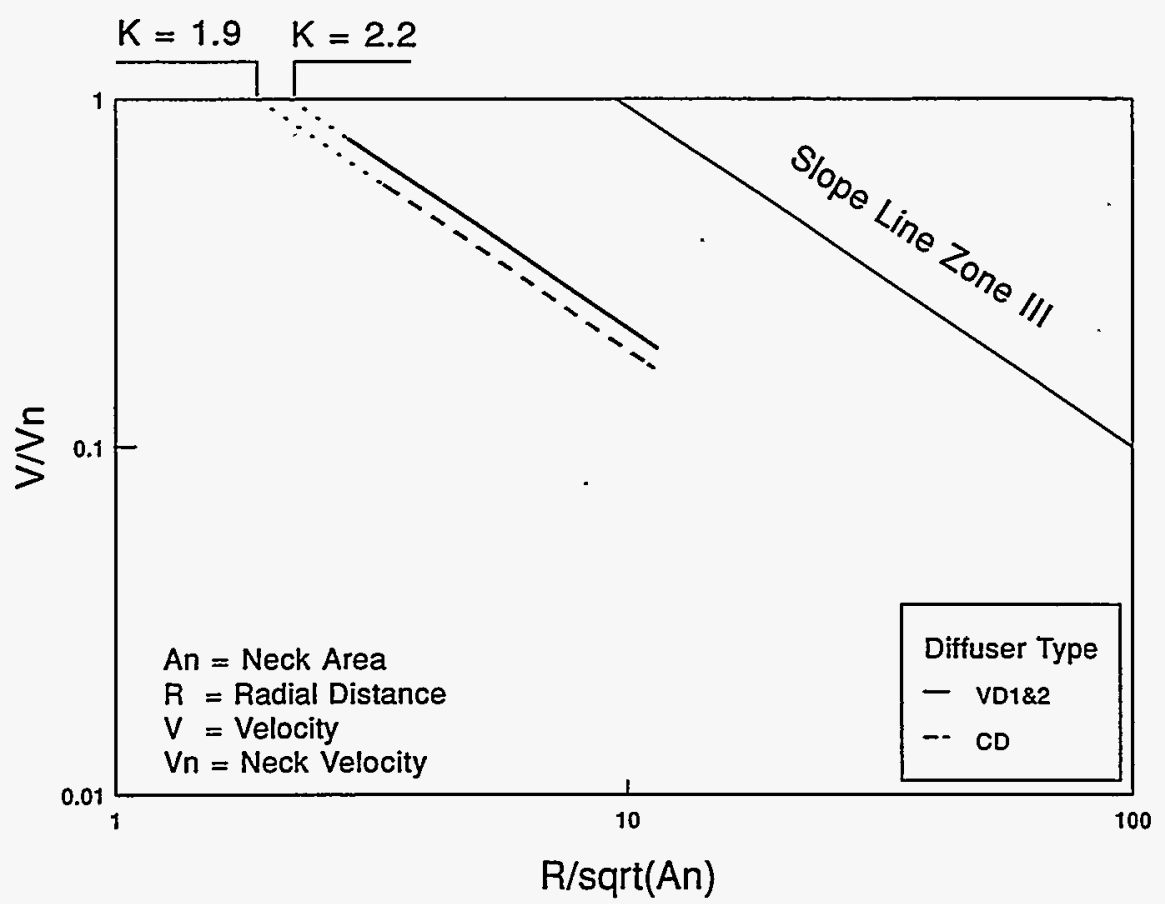

ve-hg64-a2702-13

Figure 14. Composite velocity decay for three diffusers; (A) data, (B) best-fit lines 
For a given diffuser diameter and flow rate, the diffuser with a higher $\mathrm{K}$ will produce a jet at a higher velocity, at a given radial distance. Under these circumstances, a diffuser with a higher $\mathrm{K}$ will cause more ambient air to be mixed with its jet. Thus, the vortex diffusers create somewhat more induction when compared with the conventional diffuser, which is attributable to the turbulence created at the outlet by the rotational component of the jet. However, additional research is needed to quantify this effect. It is not clear whether the induction is high enough to have a significant effect on the motion of room air.

Static pressure data, measured at 1.5D upstream of each diffuser, are presented in Figure 15. Both vortex diffusers require higher static pressure at a given flow rate than does the conventional diffuser to force the air flow through the vortex diffuser vanes. Of course, this results in a higher operational cost.

It should be noted that several of the runs for vortex diffuser \#1 were repeated after 1 month, and the results were within $4 \%$ of the first series.

\subsection{Observations and Flow Visualizations}

Three sets of information pertain to the airflow patterns. First, the general motion of air from each diffuser jet was observed. Second, a series of flow visualization photographs were obtained to show the ambient air motion near the diffuser jet. And third, whole-field visualization photographs are presented. All photographs were taken from the side of the test platform, approximately $1.8 \mathrm{~m}(6 \mathrm{ft})$ away from the center.

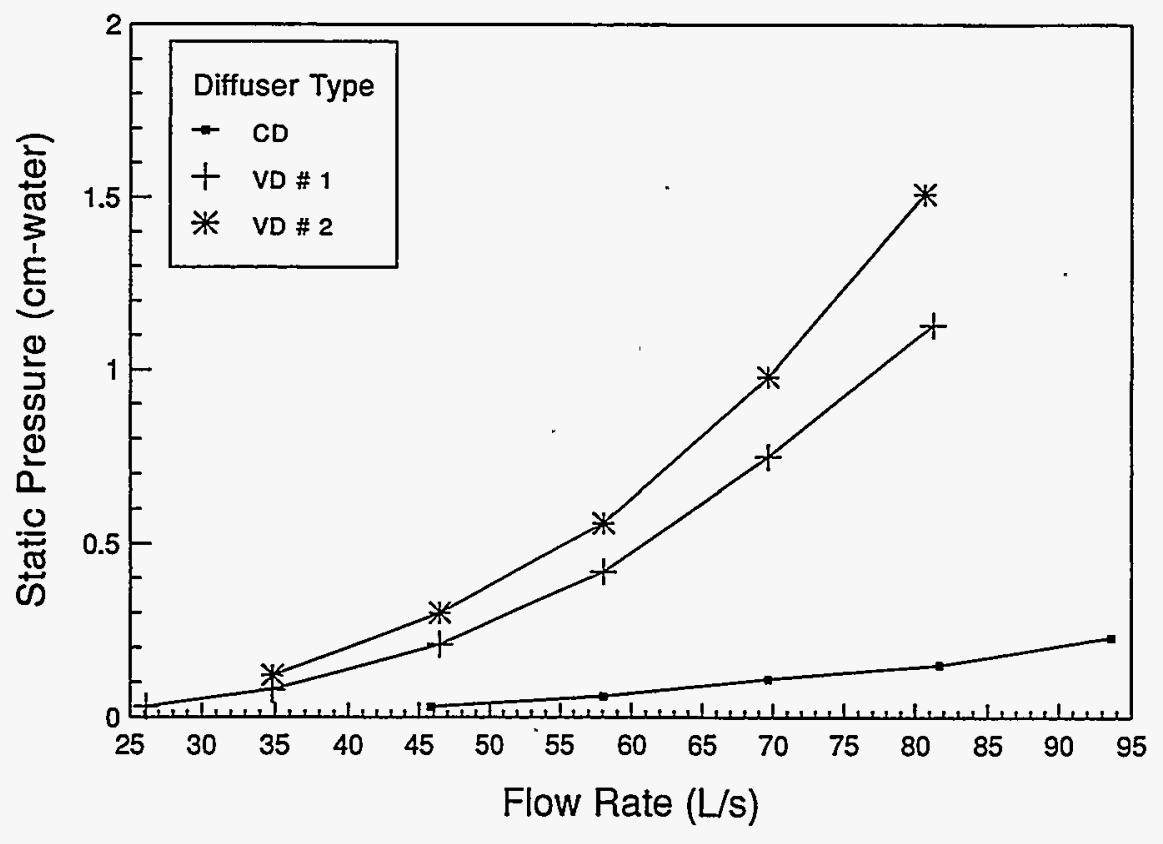

vc-hg64-a2702-14

Figure 15. Duct static pressure for three diffusers 
Numerous observations were made to determine the direction of air flow around each of the diffusers by placing a thin mylar strip in the airstream. In the case of the conventional diffuser, the direction of outflow was radial, as expected. For the vortex diffusers, a strong rotation was seen at the diffuser outlet area, but this rotational motion decayed to produce a straight radial flow within 3D of the diffuser center. In another independent test for vortex diffuser \#1, colored oil drops were placed on the diffuser face plate at different radial and angular positions, and their traces confirmed this observation.

Examples of the air motion near the diffuser jet for the conventional diffuser and for vortex diffuser \#2 at the same flow rate are shown reproduced in Figures 16 and 17. The motion is made visible by the smoke generated by three punks taped together and placed above the test platform. The white horizontal lines in the photographs are strings stretched across the platform to mark the vertical distance from the diffuser face at $30 \mathrm{~cm}(1 \mathrm{ft}), 46 \mathrm{~cm}(1.5 \mathrm{ft})$, and $61 \mathrm{~cm} 9(2 \mathrm{ft})$. A general description of these photographs follows.

Depending on where the smoke was produced, it rose (because of its buoyancy) a short distance, and then it was pulled downward into the diffuser jet, clearly showing the motion of the air near the jet. The distance the smoke rises and the amount of smoke that is pulled into the diffuser jet depend on the diffuser, and these values could be used as a qualitative measure of the mixing between the ambient air and the jet issuing from the diffuser. For example, in Figure 17(B) there is no initial rise, and all the smoke is pulled into the diffuser jet, indicating greater mixing when compared with the case shown in Figure 16(B).

From other photographs shown in Figures 16 and 17, larger mixing is apparent for the vortex diffuser for the locations observed in this study. Note that the smoke from the punks is generated by burning, and thus its use as a tracer would underestimate the downward motion of isothermal ambient air. Nevertheless, a downward motion of smoke (which is indicative of the downward motion of air) is seen in most of the photographs shown in Figures 16 and 17.

The whole-field flow visualization runs (using two visualization media-fog and smoke) were recorded on a videotape for completeness. Some photographs of the same runs are reproduced in Figures 18 and 19 for the conventional diffuser and vortex diffuser \#2 at two different flow rates. The visualizations of vortex diffuser \#1 were similar to those of vortex diffuser \#2. The diffuser jet, which was made visible by the fog, is the horizontal cloud-like portion of the photographs. The motion of the air near the diffuser jet was visualized by the smoke, which was generated by burning punks located abovethe diffuser center. The white horizontal line marks the height of $30 \mathrm{~cm}(1 \mathrm{ft})$ above the diffuser.

As seen in Figure 18(A), the smoke for the conventional diffuser is initially dispersed upward, and then a portion of it moves downward, whereas for the vortex diffuser at approximately the same flow rate, all the smoke moves downward [see Figure 19(A)]. This indicates a greater mixing between the air and the jet for the vortex diffuser. At the higher flow rate shown in Figures 18(B) and 19(B), the results are qualitatively comparable between the diffusers; i.e., the induction at the outlet is not obviously greater for the vortex diffuser. 

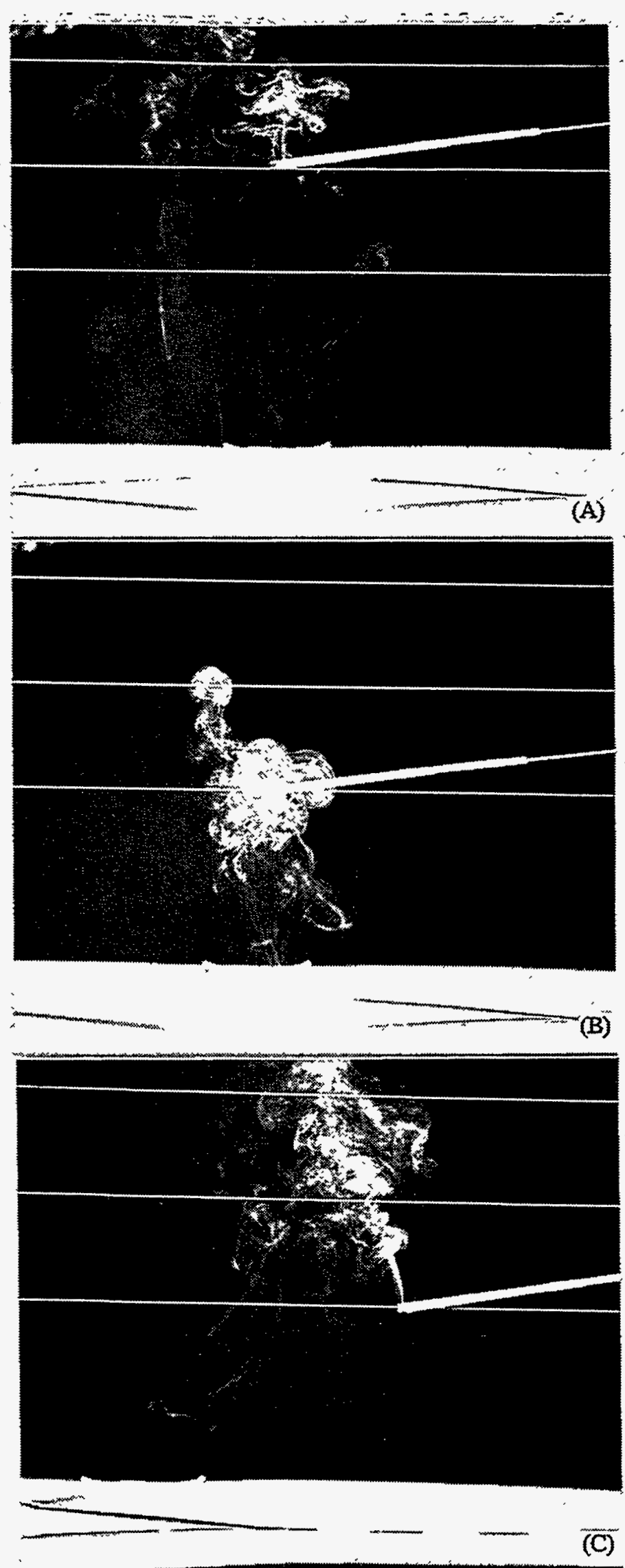

Figure 16. Ambient air motion near jet for conventional diffuser $(Q=71 \mathrm{~L} / \mathrm{s})$ : (A) $R=0$, $H=46 \mathrm{~cm}$; (B) $R=0, H=30 \mathrm{~cm}$; (C) $R=61 \mathrm{~cm}, \mathrm{H}=30 \mathrm{~cm}$ 

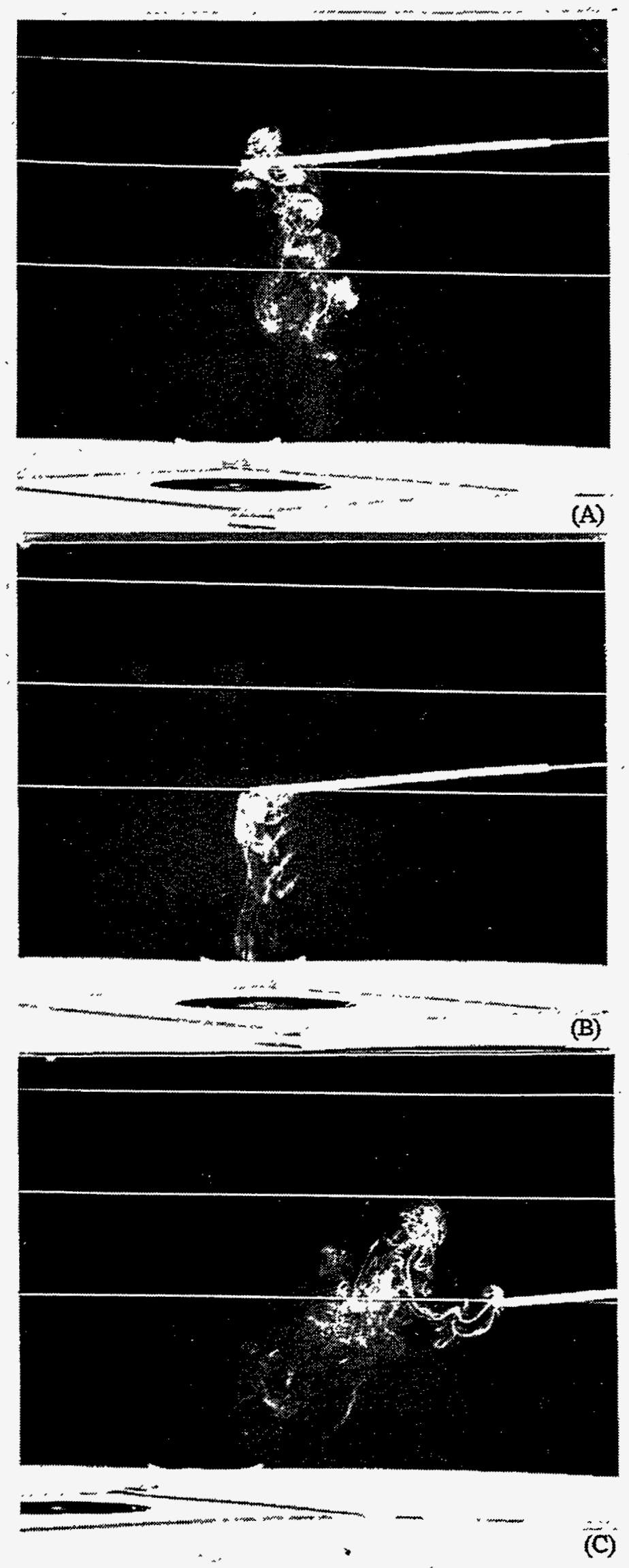

Figure 17. Ambient air motion near jet for vortex diffuser $\# 2(Q=71 \mathrm{~L} / \mathrm{s}):(A) R=0, H=46 \mathrm{~cm}$; (B) $R=0, H=30 \mathrm{~cm}$; (C) $R=61 \mathrm{~cm}, \mathrm{H}=30 \mathrm{~cm}$ 

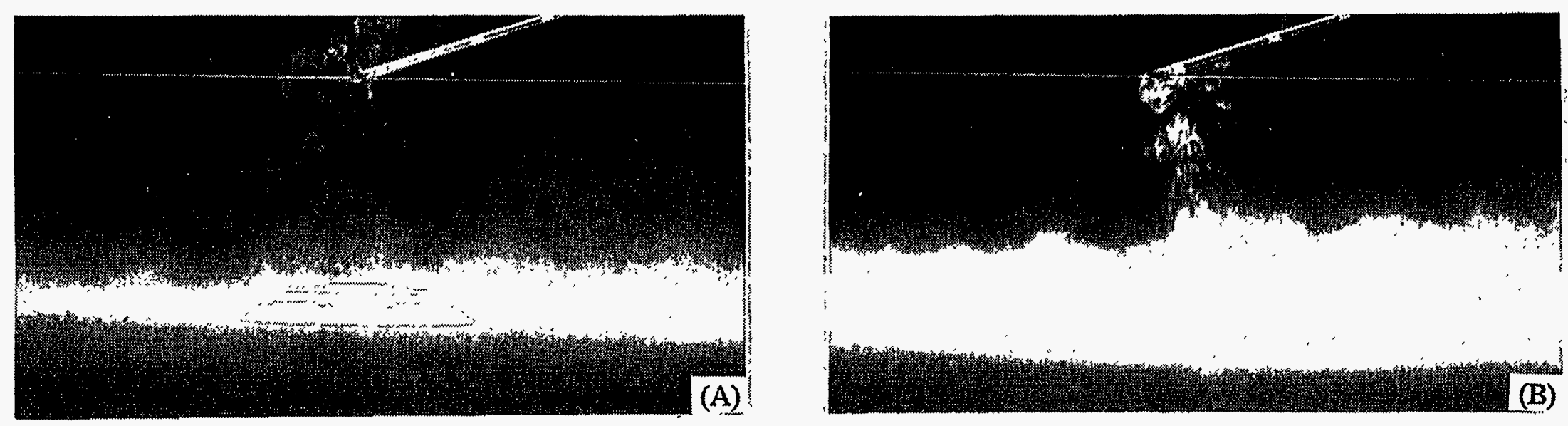

Figure 18. Whole-field flow visualization for conventional diffuser
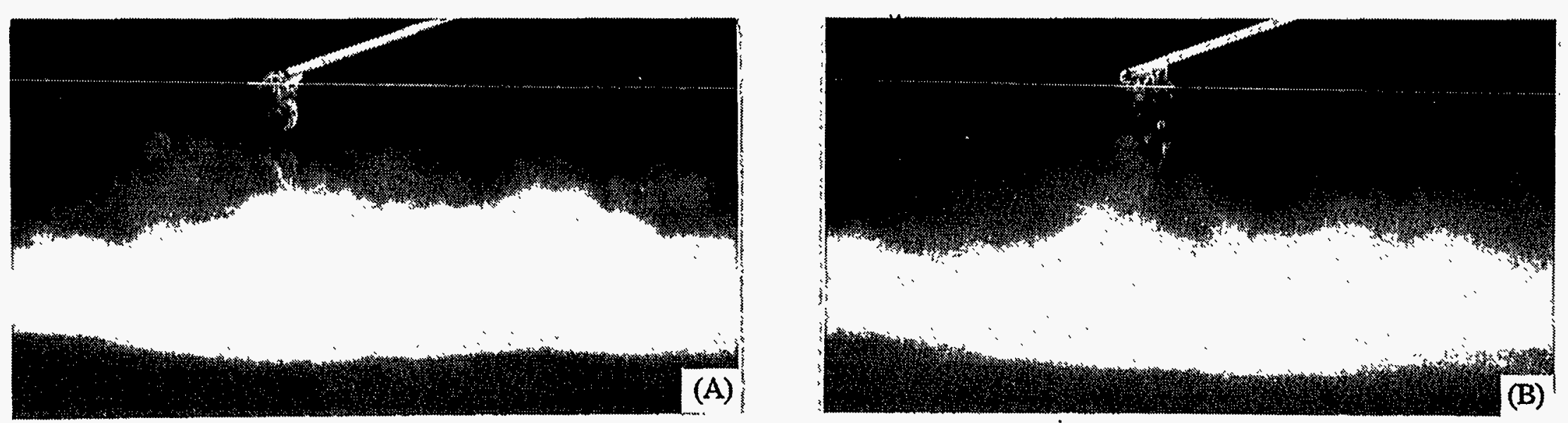

Figure 19. Whole-field flow visualization for vortex diffuser \#2 


\section{Conclusions}

Diffuser manufacturers can and should provide standard performance data for their vortex diffusers. The performance of these diffusers can be expressed by standard parameters of throw and pressure drop, at least. The following conclusions are based on the quantitative measurements and qualitative observations made in this study of vortex diffusers.

1. The jets issuing from the vortex diffusers are rotational at the outlet but turn into straight, radial flows within $3 \mathrm{D}$ of the center.

2. The maximum velocity at a given radial position occurs within $2 \mathrm{~cm}$ (1 in.) of the surface, as with a conventional diffuser.

3. Circumferentially uniform flow over $360^{\circ}$ is produced by both conventional and vortex diffusers, but, for vortex diffuser \#2, the flow's uniformity is dependent on careful vane adjustment.

4. The jet velocity decay for the vortex diffusers resembles that of the typical zone III.

5. Somewhat more induction is observed near the vortex diffuser outlet compared with that of the conventional diffuser. However, the significance of this effect on room air motion remains to be quantified.

6. The up-side-down test produces valid results as long as isothermal air is used.

7. The vortex diffusers require higher static pressure than the conventional diffusers.

8. A fog machine can be a useful device for a whole-field flow visualization in air-conditioning applications. It can easily produce a large, controllable amount of nontoxic fog. 


\section{References}

ASHRAE Handbook of Fundamentals, 1993, Atlanta, Georgia: The American Society of Heating, Refrigerating and Air-Conditioning Engineers, Inc.

ASHRAE, 1991, "Method of Testing for Rating the Performance of Air Outlets and Inlets," ANSI/ASHRAE 70-1991, Atlanta, Georgia: The American Society of Heating, Refrigerating and AirConditioning Engineers, Inc.

Koestel, A., 1957, "Jet Velocities From Radial Flow Outlets," ASHRAE Transactions, Vol. 63, pp. 505-526.

Miller, P.L., and Ball, H.D., 1983, "Results of Multilaboratory Testing of Air-Diffusion Devices," ASHRAE Transactions, Vol. 89.

Nagasawa, Y., 1992, "Some Observations on Coanda Spiral Nozzle for Exhaust Ventilation," Proceedings of Room Vent '92, pp. 141-153, SCANVAC, Oslo, Norway.

Nagasawa, Y., and Matsui, S., 1988, "Application of Spiral Vortex Flow in the Control of Indoor Air Quality," Proceedings of Room Vent '88, pp. 413-422, SCANVAC, Oslo, Norway.

Nagasawa, Y., Nitadori, M., and Matsui, S., 1990, "Characteristics of Spiral Vortex Flow and Its Application to Control Indoor Air Quality," Proceedings of Room Vent '90, pp. 1-16, SCANVAC, Oslo, Norway.

Yamaguchi, S., Ochi, H., Matsui, S., and Ishiguro, Y., 1991, "Contamination Control by Means of Artificial Tornado," Proceedings of Room Vent'91, SCANVAC, Oslo, Norway. 
Appendix 
Theatrix, Inc.

1630 Wrest Evas, Unit $C$

Englewoos, CO 80110

(303) 922-0505

\section{model 4500 fog machine}

\section{WHEN BILLOWING CLOUDS OF DENSE FOG ARE NEEDED, THE 4500 FOG MACHINE IS THE ANSWER}

\author{
- High volume, dense fog \\ - Internal/external tank capabilities \\ - Volume control \\ - Uses proven Rosco Fog Fluid
}

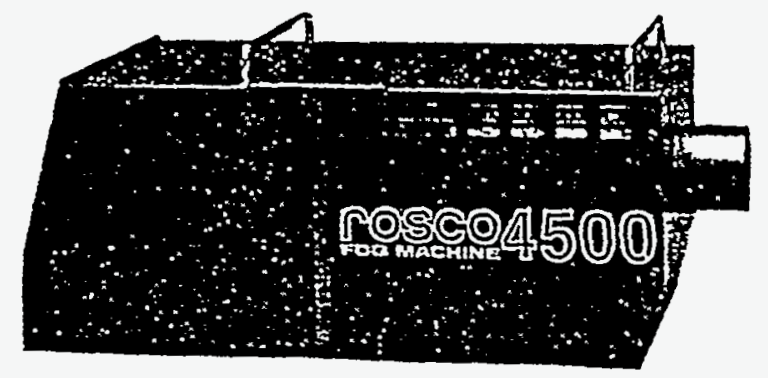

Controls and indicator lights for the Model 4500 are protecled by a metal cover at the rear of the 40 pound (18.2 Kg) machine.

Rosco's Model 4500 Fog Machine is the latest in the growing line of Rosco fog systems. The machine has an output of 4500 cubic feet per minute, three times the output of the Model 1500.

The Model 4500 utilizes most of the quality components which have proven so reliable in the 1500 . The high volume of smoke is generated by combining three heat exchangers fed by a powertul peristaltic pump. The speed. of the pump is controlled electronically, thus controlling the volume of the fog.

The Model 4500 features an intemal $1 \% / 2$ liter tank for fluid. The fluid level in the intemal tank can be monitored from outside the machine. Users who prejer to supply fluid from larger extemal containers can do so easily with a simple hose connection.

The 4500 has an extensive array of controls and indicator lighls on the back of the machine,

* Rosco's Model 1500 was uved in the study reported here.

$11 / 89(5.1)$
Rosco Laboratories, Inc. Roseo Laboratories, Lid.

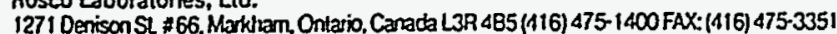
Roscolab Ltd. (01) $659-2300$ Tetex: 8953352
36 Bush Ave. Fort Chester, NY 10573(9;4) 037.3300 FAX: (914)937.5984 Telex: 131472 1135 North Highland Ave. Hollywood, CA 90038 (213) 462-2233 FAX: (213) 462-3338

Brancthard Works Kangley Bridge Rd. Sycontram. London SE26 5 SAO Engtand secured under metal cover. There is a remole control included as standard equipment with the machine which permits operation from as far away as 100 feet. Also available is an optional Super Remote that includes a programmable sequencer. The machine is available in both 120 volt and 240 volt models.

The Model 4500, like all Rosco Fog Products, uses Rosco Fog Fluid exclusively. Rosco Fog Fluid is a unique chemical formulation. As reported in a National Institute of Occupational Salety and Health (NIOSH) study (HETA 88-117): "Two main advantages to the Rosco system are the low toxicity of the components which comprise the liquid smoke solutions and the fact that the aerosol generated has no unpleasant odor, leaves no residue and does not irritate the eyes or mucous membranes."
Rosco España. S.A

Pilar De Zaragoza 37, Madrid 28, Spain (01) 246-1102 Telex: 42710 Altn: $42-00802$

Rosco Portuguese Lda.

iv Benlo Gonclaves, 68 Bairto de Angoia. Camarale. Portugal 2685 Sacaren 
POWER REQUIREMENTS: 240 volts, $50 / 60 \mathrm{~Hz}, 12.5$ amps 120 volts, $50 / 60 \mathrm{~Hz}, 20$ amps

MAXIMUM FLUID CONSUMPTION: 5.25 liters per hour

SMOKE OUTPUT: $\quad 4500 \mathrm{cu}$. ft. per minute

PARTCLESRE: $\quad 0.5-60$ microns

WARM UP TMME: 10 minutes (approx.)

WEGHT: $\quad 40 \mathrm{lbs}$.

Dimensions: $\quad 24.5^{\prime \prime} \times 9.0^{\prime \prime} \times 9.75^{\prime \prime}$ 


\author{
I PRODUCT IDENTIFICATION

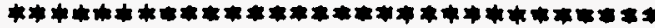 \\ Manufacturer's Name: \\ ROSCO LABORATORIES INC. \\ Regular Telephone No: \\ (914) 937-1300 Eastern Time \\ (213) 462-2233 Pacific Time \\ Emergency No: \\ (nights/weekends) \\ (914) 738-9169 \\ (203) $327-3244$
}

Address:

36 Bush Ayenue, Port Chester, New York 10573

Product Name:

ROSCO FOG FLUID

Synonyms:

Rosco Fog and Smoke Fluid. Rosco Smoke Simulation Fiuid, Rosco Stage and Studio Fluid

\title{
II HAZARDOUS INGREDIENT
}

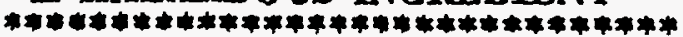

\section{Material or Component}

The fog fluid, which is unique in the marketplace, is a proprietary mixture of yery low toxicity ingredients. All major components are essentially non-toxic when ingested, are "Generally Regarded as Safe" by the U.S.Food and Drug Administration (FDA), and have been individually approved by FDA for use either in foods, food additives, pharmaceutical preparations, or food packaging. Proprietary information is available at any time to licensed physicians solely for treatment of their patients.

Occupational exposure limits (PELs or TLVs) have not been established for any of the components of this product.

III PHYSICAL DATA

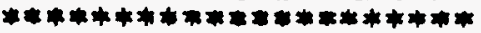

Bolling Point (760 mmHg) : 212-470 F

Specific Gravity $\left(\mathrm{H}_{2} \mathrm{O}=1\right): 1.12$

Vapor Density (air=1) : 2.9

\%olatiles by Vol.: $16 \%$

Molecular Weight : Range (18-150)
Melting Point: not applicable

Papor Pressure: $8.4 \mathrm{mmHg}$

Solubility in water:

Complete@70F

Evaporation Rate ( $N=1): 0.01$ (N=butyl acetate)

Molecular Composition:

Appearance \& Odor: Green or coloriess liquid with pleasant mild odor. 
IV FIRE AND EXPLOSION DATA

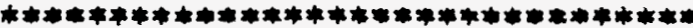

Flash Point: no flash point by Cleveland Open Cup and Penskey-Martin Closed Cup

Autoignition Temp.: Not Determined

Flammable Limits in Air \% by Vol.: Not Determined

Extinguishing Medis: WATER FOG, ALCOHOL FOAM, DRY CHEMICAI

Special Flre Fighting Procedures: NONE

Unusual Fire and Explosion Hazard: NONE

$\checkmark$ HEALTH HAZARD INTORMATION

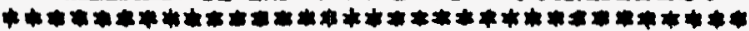

Routes of Exposure

Inhalation: (Vapor)

The low volatility of the compounds in this fomulation makes it highly unlikely that significant quantities of yapor could be absorbed during exposure either to the liquid or to the fog.

Inhalation: (Acrosol)

The fog includes liquid particles which may be inhaled and subsequently exhaled, absorbed or swallowed.

Skin Absorption:

The fluid can be very slowly absorbed through intact skin. Significant exposures could only be acquired by immersion in fluid or prolonged contact with saturated clothing.

Entects of Orer-exposure

Ingestion:

Very low toxiciry, Central nervous system depression (stupor) in children and drowsiness or dizziness in adults at doses of $2-3$ ounces. Rapid heart rate and breathing rate in response to decrease in blood $\mathrm{pH}$.

Inhalation:

Acute vapor exposure is difficult to achieve at ambient temperature. There is little likelihood of adverse effects. Sensitive persons (such as those with asthma or other reactive airway disorders) including employees or spectators, should be wamed that they may experience asthma-like effects from aerosol exposures.

Skin contact:

Fuid may cause slight irritation after prolonged contact. Incidental skin contact with the fog should produce no adverse effect.

Eye contact:

May cause mild irritation. 
Chronic:

No long term effects are known to result from exposure by inhalation or by contact with intact skin.

\section{Emergency and First Ald Procedures}

Ejes: In case of cye contact with liquid, flush immediately with large amounts of water and seek aid of a physician.

Skin: $\quad$ Short term contact causes no adverse effects.

Wash off with water and remove saturated clothing.

Inhalation: Remove person to fresh air. If breathing has stopped, administer cardio-puimonary resuscitation (CPR).

Ingestion: Very low in toxicity. Consult physician if symptoms of intoxication appear. Do not induce yomiting if patient is not fully conscious. Small amounts of fluid are metabolized or excreted without adverse effect.

Note to Physician: Ingestion of several ounces by a child (proportionally more in an adult) could result in metabolic (lactic) acidosis. The $\mathrm{pH}$ imbalance bas been successfilly treated with bicarbonace. Treat respiratory effects symptomatically.

\section{REACTIVITY DATA}

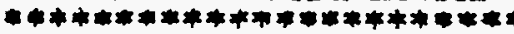

Conditions Contributing to Instability: Stable Compound

Incompatibillty: Oxidizing Materials (strong acids or peroxides)

Hazardous Decomposition Products: None

Conditions Contributing to Hazardous Polymerization: Does not occur

$$
\text { VII SPILL OR LEAK PROCEDURES }
$$

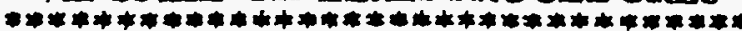

\section{Steps to be Taken if Material is Released or Spilled}

Small Spills: Soak up with absorbent material and sweep into drum.

Large Spills: Dam to prevent run-off to storm sewers or waterways. Use vacuum system to recover.

Neutralizing Chemicals: not applicable

Waste Disposal Method: Contact commercial chemical waste company to dispose of waste in accordance with federal, state, and locai regulations. 
VIII SPECIAL PROTECTION INFORMATION

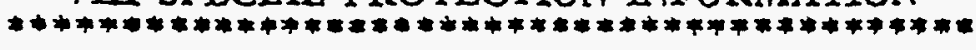

\section{Yentilation Requirements}

Special yentilation is not required where ambient indoor air quality is adequate (see ASHRAE Standard 62-1981). For applications in totally enciosed, unventilated spaces see OSHA, Yotice of Proposed Rulemaking; 1910.146 dated June 6, 1989: Confined space.

Specific Personal Protective Equipment

Respiratory :

None requined for intermittent, short-term exposures. Organic yapor respirators with partculate filters can be used to decrease exposure.

Eye:

Chemical face shields or goggles are recommended to prevent eye contact with the fluid.

\section{Skin:}

Aprons and/or gloves made of neoprene, rubber, or other impervious material can be used to prevent exposure.

Other Clothing and Equipment:

Practice reasonabile caution to miniuize skin contact.

\section{SPECIAL PRECAUTIONS}

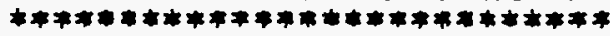

Precautionary Statements: not applicable

Other Handling and Storage Requuirements: not applicable

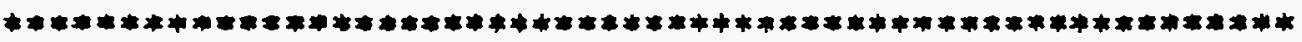

SUPERFUND AMENDMENT REAUTHORIZATION ACT (SARA)

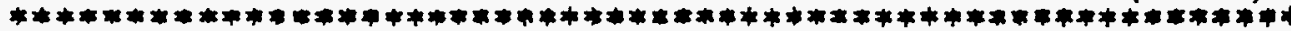

SARA Title III Emergency Planning and Community Right-10-Know Act (EPCRA) Section 313:

Since they are individally listed by the US Food and Drug Administration as substances "Generally Regarded as Safe" for use in Food or in Food Packaging, components of this product are exempt from the reporting requirements of Section 313 of EPCRA.

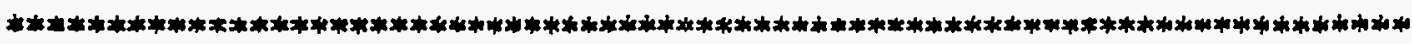

Prepared By: $\quad$ Stan Miller, President

Rosco Laboratories

Address: $\quad 36$ Bush Avenue

Port Chester, NY 10573, USA

Date: $\quad$ January, 1994 


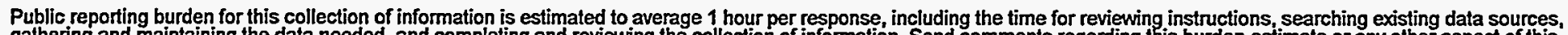

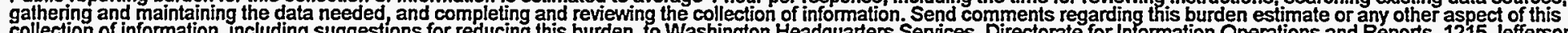

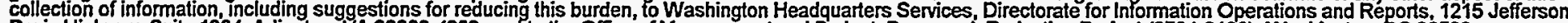

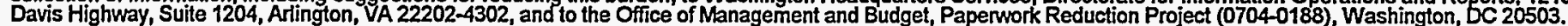

\begin{tabular}{l|l|l|l}
\hline 1. AGENCY USE ONLY (Leave blank) & $\begin{array}{c}\text { 2. REPORT DATE } \\
\text { October 1995 }\end{array}$ & $\begin{array}{l}\text { 3. REPORT TYPE AND DATES COVERED } \\
\text { Technical Report }\end{array}$ \\
\hline 4. TITLE AND SUBTITLE & & 5. FU
\end{tabular}

\author{
4. TITLE AND SUBTITLE \\ Experimental Study of Vortex Diffusers
}

5. FUNDING NUMBERS

(TA) 8E51.1006

\author{
6. AUTHOR(S) \\ Said Shakerin, Paul L. Miller
}

\title{
7. PERFORMING ORGANIZATION NAME(S) AND ADDRESS(ES)
}

National Renewable Energy laboratory

1617 Cole Boulevard

Golden, CO 80401-3393

8. PERFORMING ORGANIZATION REPORT NUMBER

NREL/TP-472-7331

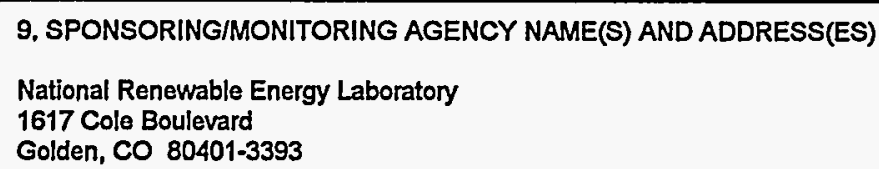

\section{SUPPLEMENTARY NOTES}

\section{2a, DISTRIBUTION/AVAILABILITY STATEMENT}

National Technical Information Service

U.S. Department of Commerce

5285 Port Royal Road

Springfield, VA 22161 12b. DISTRIBUTION CODE

UC-1600

\section{ABSTRACT (Maximum 200 words)}

This report documents experimental research performed on vortex diffusers used in ventilation and air-conditioning systems. The main objectives of the research were (1) to study the flow characteristics of isothermal jets issuing from vortex diffusers, (2) to compare the vortex diffuser's performance with that of a conventional diffuser, and (3) to prepare a report that disseminates the results to the designers of ventilation and air-conditioning systems. The researchers considered three diffusers: a conventional round ceiling diffuser and two different styles of vortex diffusers. Overall, the vortex diffusers create slightly more induction of ambient air in comparison to the conventional diffuser.

\section{SUBJECT TERMS}

vortex diffusers, ventilation, air-conditioning, isothermal jets, diffuser area factor, diffuser neck area, diffuser neck diameter, average outlet velocity, neck velocity, rotational velocity, translational velocity

15. NUMBER OF PAGES 34

16. PRICE CODE

A.03

17. SECURITY CLASSIFICATION OF REPORT
18. SECURITY CLASSIFICATION OF THIS PAGE
19. SECURITY CLASSIFICATION OF ABSTRACT
20. LIMITATION OF ABSTRACT

Standard Form 298 (Rev. 2-89)

Prescribed by ANSI Std. Z39-18 


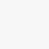


